\title{
PROCESSOS MINERALIZADORES EM BACIAS TARDI-OROGÊNICAS 1. INFLUÊNCIA DAS ESTRUTURAS RÍGIDAS NA GERAÇÃO DOS DEPÓSITOS DA MINEPAR E DO RIBEIRÃO DA PRATA, GRUPO ITAJAÍ (SC)
}

\author{
JOÃO C. BIONDI*, GERNOT SCffICKET** ADONIRAN BUGALHO*
}

\begin{abstract}
ORE GENESIS IN TARDI-OROGENIC BASINS -1. RIGID STRUCTURES INFLUENCE ON THE GENESIS OF MINEPAR (Au) AND RIBEIRÃO DA PRATA (Pb-Zn-Cu) DEPOSITS, ITAJAI GROUP (SC BRAZIL). Gold quartz veins (MINEPAR PTY) outcrops in the northen border of Itajai Group. The Ribeirão da Prata $(\mathrm{Pb}-\mathrm{Zn}-\mathrm{Cu})$ deposit is related with the Perimbo fault, at the southern border of the same Group. Structural analysis of the granulitic basement and the detritic sedimentary rocks fractures, where the gold veins outcrop, indicate that ore was formed in different phases of the orogenesis that deformed the Itajai Group. During the first phase, a SENW displacement reactivated ancient basement faults of Gaspar region, generating a transpressional system where gold basement veins originates (Schramm and Subida veins, with high Augrade and low $\mathrm{Ag}$ and $\mathrm{Bi}$ ). In the second, final, phase, now as a transtensional system, quartz veins of the sedimentary covering were generated (with low $\mathrm{Au}$ and $\mathrm{Bi}$ grades, without Ag). In Ribeirão da Prata region, the first, transpressional, deformational phase reactives the Perimbo fault with reverse mouvement The ore body was crossed by secondary low angle faults and their border were modified by the principal fault, indicating that ore genesis predates the reactivation. The ryolitic volcanism in Ribeirão da Prata region is post-deformational, so it is not genetically related with $\mathrm{Pb}-\mathrm{Zn}-\mathrm{Cu}$ ore. It must be verified the relation between granites and the ore.
\end{abstract}

Keywords: Mineral deposit, structural control, Itajai Group.

\begin{abstract}
RESUMO Veios de quartzo com ouro (MINEPAR) afloram na borda norte da bacia do Grupo Itajaí, na região de Gaspar. Na borda sul, na região do Ribeirão da Prata, há um depósito de Pb-Zn-Cu. Ambos mostram um relacionamento direto com estruturas rígidas que afetam rochas do Grupo Itajaí. A análise estrutural das fraturas do embasamento granulítico e da cobertura sedimentar detrítica, onde afloram 44 veios de quartzo com $\mathrm{Au}$, indica que o minério foi gerado em diferentes fases da orogênese que deformou o Grupo Itajaí. Na primeira fase, uma compressão dirigida de SE para NW reativou antigas falhas do embasamento da região de Gaspar. Esta compressão gerou um sistema transpressional no qual se formaram os veios de quartzo do embasamento (veios do Schramm e da Subida, com alto teor de $\mathrm{Au}$, pouca $\mathrm{Ag}$ e pouco Bi). Na parte sul da bacia, a primeira deformação, transpressional, reativou a falha do Perimbó gerando movimentos reversos ao menos na área do Ribeirão da Prata. O corpo mineralizado com $\mathrm{Pb}-\mathrm{Zn}-\mathrm{Cu}$ foi fatiado por falhas secundárias de baixo ângulo e os seus limites foram modificados pela falha principal, mostrando que o minério é mais antigo que a reativação. Os riolitos aflorantes na região do Ribeirão da Prata não foram afetados pelas deformações mencionadas. Seriam, portanto, posteriores a mineralização de $\mathrm{Pb}-\mathrm{Zn}-\mathrm{Cu}$. Resta analisar a possibilidade da existência de uma relação genética entre os granitos da região e essas mineralizações.
\end{abstract}

Palavras-chaves: Depósito mineral, controle estrutural, Grupo Itajaí.

INTRODUÇÃ̃O Desde os anos 10, são conhecidas as mineralizações de ouro do Ribeirão do Arraial, próximo a Gaspar, e as mineralizações de chumbo, cobre, zinco e prata (?) do Ribeirão da Prata (Ferraz 1921). A MINEPAR (Mineração Gaspar Ltda.) lavra os aluviões do Ribeirão do Arraial há mais de 20 anos, voltando-se, recentemente, para a prospecção e a lavra do minério primário filoneano. O Ribeirão da Prata foi lavrado intermitentemente, por diversas empresas, desde 1918. Em 1974, a DOCEGEO interessou-se pelo depósito, nele realizando trabalhos de pesquisa (de Ferran \& Kishida 1974) que concluíram pela existência de "reservas marginais", e permitiram sugerir o prosseguimento dessa pesquisa, com sondagens e geoquímica.

Em 1990, o Departamento de Geologia da Universidade Federal do Paraná iniciou um projeto intitulado "Avaliação do Potencial Metalogenético do Grupo Itajaí". Desde 1991, este projeto passou a ser apoiado pelo CNPq (bolsa individual de pesquisa e bolsas de iniciação científica) e pelo PADCT-FINER O trabalho agora apresentado se enquadra e é parte desse projeto.
GEOLOGIA REGIONAL E LOCAL Os filões auríferos da Minepar situam-se na borda norte da região de afloramento das rochas do Grupo Itajaí, próximo à cidade de Gaspar. O Ribeirão da Prata situa-se na borda sul do mesmo grupo, a $22 \mathrm{~km}$ ao sul da cidade de Blumenau (Fig. 1).

Geologia regional O Grupo Itajaí (Schulz et al 1970, Kaul 1976 e Silva \& Dias 1981) aflora como um conjunto de sedimentos predominantemente detrítícos, encimados e atravessados por granitos e riolitos, aflorantes sobretudo no extremo oeste da bacia sedimentar do Itajaí (Fig. 1). Esta bacia é alongada e limitada, na maior parte do seu perímetro, por falhas e zonas de cisalhamento que a separam do Complexo Granulítico de Santa Catarina. A oeste, a bacia sedimentar do Itajaí é recoberta por rochas da bacia do Paraná. As rochas do Grupo Itajaí têm idades variadas entre $580 \pm 40 \mathrm{Ma}$ e $540 \pm 10 \mathrm{Ma}$, tendo sido submetidas a um anquimetamorfismo há cerca de $535 \mathrm{Ma}$ (Basei 1985). A história geológica do Grupo Itajaí foi sumarizada, recentemente, por Basei $(1985)$, Basei et al (1987), Silva (1987), Krebs et al (1988, 1990 a,b), Appi 

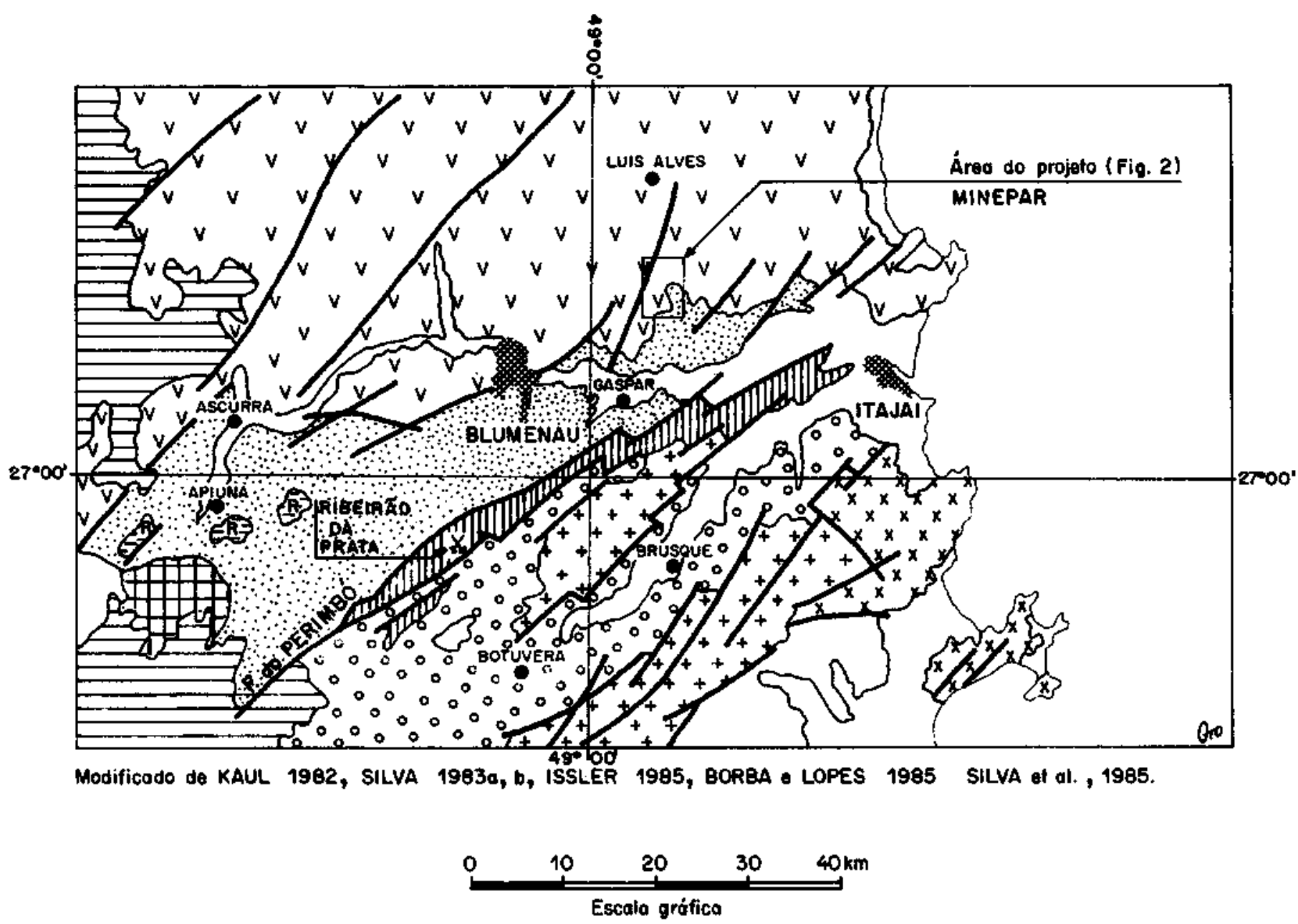

QUATERNÁRIO

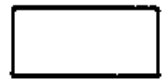

PALEOZÓICO

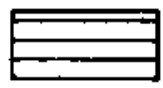

Bacio do Paraná.

PALEOZÓICO SUPERIOR

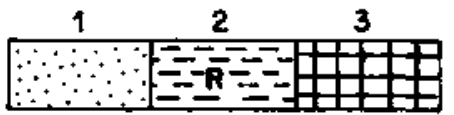

1 - Coberturo vulcano-sedimentar - Grupo ltajaí.

2. Corpos intrusivos rioliticos - Riolito Apiúno.

3 - Corpos intrusivos graniticos - Granito Subida.
PROTEROZÓICO SUPERIOR A MÉDIO

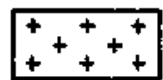

Granitóides intrusivas - Gronodiorito Volsungana.

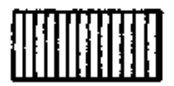

Zono rúptil Hejai - Gaspar (Faixa do Ribeirōo da Prata).

\section{AROUEANO}

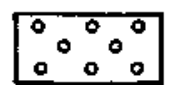

Complexo metamórfico Brusque.

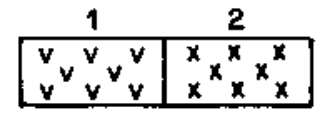

1 - Complexo de Luís Alvos.

2 - Complexo de ttapemo-Porto Belo.

Figura 1 - Mapa geológico regional simplificado mostrando a localização das áreas com quartzo aurífero (Minepar) e com Pb-Zn$\mathrm{Cu}$ (Ribeirão da Prata - SC)

Figure 1 - Regional geological map showing the location of the area with gold veins (Minepar) and with Pb-Cu-Zn (Ribeirão da Prata - Santa Catarina State/Brazil) 
(1988, 1991), Appi et al. (1987, 1990) e Rostirolla (1991). Conforme o enfoque adotado pelos diferentes autores, muda o nome das unidades que constituem o Grupo Itajaí. Schulz et al (1970) denominam a unidade basal de Formação Garcia, a unidade intermediária de Formação Campo Alegre e a unidade superior de Formação Baú. Kaul (1976) e Silva \& Dias (1981) mantêm a mesma denominação de Schulz et al (1970), mas englobam a Formação Baú na Campo Alegre. Basei (1985) divide o Grupo em Unidade Arenítica Inferior e Unidade Síltica Superior. Appi \& Souza Cruz (1988) inicialmente denominam a unidade basal de Formação Gaspar e a superior de Formação Campo Alegre, e as identificam geneticamente como continental e como subaquosa bacinal, respectivamente. Posteriormente Appi (1991) adota o nome de Seqüência Garcia para a unidade superior, e Seqüência Gaspar para a inferior. Rostirolla (1991) fez uma subdivisão genética e identificou quatro unidades, denominadas, da base para o topo, unidade A (sistemas de leques aluviais e deltaicos das margens NE e NW), unidade B (sistemas de leques subaquosos de água profunda), unidade $\mathrm{C}$ (sistemas transgressivos) e unidade $\mathrm{D}$ (sistemas de leques deltaicos das margens $\mathrm{S}$ e $\mathrm{SE}$ ).

Todos esses autores reconheceram a presença de domos riolíticos e graníticos na porção oeste, aflorante, do Grupo Itajaí, além da presença esparsa de diques riolíticos e riodacíticos e de tufos em diversas outras regiões. O magmatismo concentrou-se no final do preenchimento da bacia, aflorando em meio as rochas das unidades superiores (Formação Campo Alegre ou Seqüência Garcia ou unidade $\mathrm{C}$, conforme o autor). Após o término do magmatismo $( \pm 541 \pm 26 \mathrm{Ma})$ toda a região sofreu um metamorfismo de grau incipiente (anquimetamorfismo) que possibilitou o aparecimento de sericita em algumas rochas $(534 \pm 4 \mathrm{Ma})$. Este metamorfismo se associou à primeira e mais importante fase de dobramento e falhamento que afetou o Grupo, correspondente à terceira fase de deformação do Escudo Catarinense (Basei 1985).

A norte, o Grupo Itajaí faz contato com o Complexo Granulítico do Luis Alves (Fig. 1), constituído por gnaisses e granulitos. Este complexo contém granulitos (30-65\% de plagioclásio, $0-42 \%$ de ortoclásio, $0-50 \%$ de microclínio, $2-40 \%$ de quartzo, $0-10 \%$ de diopsídio, $0-60 \%$ de hornblenda, $0-10 \%$ de "hiperstênio" e $0-7 \%$ de biotita, além de até $4 \%$ de opacos mais, a nível de tração ou com ocorrência local, apatita, zircão, rutilo, clorita, epídoto, titanita, actinolita, carbonato, oxido de ferro, talco, serpentina e sericita), "hiperstênio" gnaisses quartzo feldspáticos, biotita gnaisses e migmatitos bandados, além de blastomilonitos e protomilonitos derivados dessas rochas. Entre as rochas menos deformadas predominam os noritos e enderbitos, secundados por piroxenitos e hornblenda piroxenitos. Não são raras as ocorrências de quartzitos e quartzitos ferruginosos. Todas essas rochas teriam uma idade mínima de 2,8 Ga (Basei 1985).

Regionalmente, é observada uma foliação caracterizada pelo alinhamento de minerais máficos, paralela ao bandamento dos níveis gnaíssicos e dos migmatitos estromáticos. Normalmente a orientação dessa foliação é NE com sentido de caimento variado ( $\pm \mathrm{N} 30 \mathrm{E}, 70-80 \mathrm{NW}$ ou SE). Localmente, a exemplo da região do depósito da Minepar, esta foliação tem direções NW e é verticalizada (moda N26W, 86 NE, Fig. 9). Toda a região do Complexo Luis Alves foi cisalhada, gerando zonas de milonitos orientadas entre N25E e N45E, com foliação milonítica verticalizada. Ao menos na área próxima à Minepar estas zonas de cisalhamento foram reativadas em condições rúpteis, proporcionando o aparecimento de cataclasitos (Fig. 2).

A sul, as rochas do Grupo Itajaí fazem contato com rochas do Complexo Taboleiro (ou faixa Ribeirão da Prata de Basei 1985, e Rostirolla 1991) ou com os xistos do Grupo Brusque (Fig. 1). Em ambos os casos o contato dá-se através de uma extensa zona de falha denominada Perimbó (lineamento Perimbó, Silva \& Dias 1981).
A faixa Ribeirão da Prata, mapeada por Borba \& Lopes (1983), corresponde à faixa Itajaí-Faxinal do Complexo Taboleiro, de Silva (1987). Contém as litologias do Complexo Granulítico de Santa Catarina retrabalhadas, no Brasiliano, por falhamentos inversos que tiveram deslocamentos de SE para NW. É uma região de intensa granitogênese que gerou granitos rosados e cüoritos cinzentos, isótropos. Hornblenda gnaisses, granitos foliados e hidrotermalizados e riolitos são comuns nas proximidades do Ribeirão da Prata, além de xistos com muscovita e biotita.

Geologia local VEIOS DE QUARTZO AURÍFEROS (MINEPAR) Estes veios afloram na região próxima ao contato entre o embasamento e os conglomerados e arenitos do Grupo Itajaí (Fig. l e detalhe na Fig. 2), a norte da cidade de Gaspar. No local o embasamento é constituído por noritos e enderbitos foliados, mesclados a hornblenda gnaisses, quartzitos e quartzitos ferruginosos. Milonitos, filonitos e quartzitos blastomiloníticos não são raros. Identificam zonas de cisalhamento que, ao menos em parte, foram reativadas em condições rúpteis, proporcionando a formação de brechas e geração de falhas preenchidas por pó de rocha (gouge).

O Grupo Itajaí é composto por arenitos líticos, imaturos que gradam para arenitos conglomeráticos. Conglomerados polimíticos constituem cunhas e lentes intercalados nos arenitos líticos.

A leste afloram pequenas intrusíes de riolitos, riodacitos e traquitos provavelmente da Formação Campo Alegre. Diques com estas composições, geralmente orientados N70-90E, atravessam rochas de todas as unidades do Grupo Itajaí e o embasamento. A área é recortada por falhas, constatadas e fotointerpretadas, que parecem formar três grupos com orientações diferentes. Sobre o Grupo Itajaí, a principal orientação varia entre N70-90E. Este grupo de falhas é secundado em importância por falhas orientadas NO-20E que, na região, geralmente fazem o limite NW dos sedimentos com o embasamento. Falhas com estas orientações só comuns também no embasamento. Finalmente, ocorrem também sobre a cobertura sedimentar e o embasamento, falhas orientadas N60-80W que, ao menos em parte, fazem o contato norte, local, da bacia do Grupo Itajaí. Existem várias outras orientações, menos importantes, que no se expressam com dimensões suficientes para serem mapeadas na figura 2 . Todas as orientações medidas na área serão discutidas posteriormente

O ouro tem sido lavrado sobretudo nas aluviões do córrego Santa Rosa, na parte oeste da área mapeada. Este ouro provém do desmantelamento dos veios de quartzo que ocorrem no embasamento (veios do Schramm e Subida) e em meio às rochas do Grupo Itajaí (veios do Baiano, Carlinhos, Atoleiro, Boa Vista, Limo, Cevai e Lagoa), conforme mostrado na figura 2.

HIDROTERMAUTOS COM Pb, Cu E Zn (RIBEIRÃO DA PRATA) O depósito do Ribeirão da Prata situa-se dentro de uma faixa de rochas muito cisalhadas que marca a zona da falha do Perimbó. Esta faixa de rochas cisalhadas tem 200-250 $\mathrm{m}$ de largura e faz o contato entre conglomerados do Grupo Itajaí (unidade D, de Rostirolla 1991) e gnaisses e milonitos da faixa Ribeirão da Prata (Complexo Taboleiro, Fig. l e detalhe na Fig. 3). A falha do Perimbó é uma estrutura complexa onde mesclaram-se movimentos reversos, aparentemente predominantes, com deslocamentos dextrógiros. Na região do Ribeirão da Prata, a sua atitude varia entre N60-75E, 50-60 SE. Mostra algumas características de zona de cisalhamento dúctil reativada em condições rúpteis. Nos afloramentos e nas galerias da mina os principais indicadores cinemáticos são sigmóides, degraus (raros), ou, mais freqüentes, as estrias de deslizamento. Estas feições, associadas à geometria e às características das falhas conjugadas observadas nas galerias (Fig. 8), indicam um movimento reverso dextral, com deslocamento mergulho acima. As rochas cisalhadas pertencentes à falha do Perimbó 


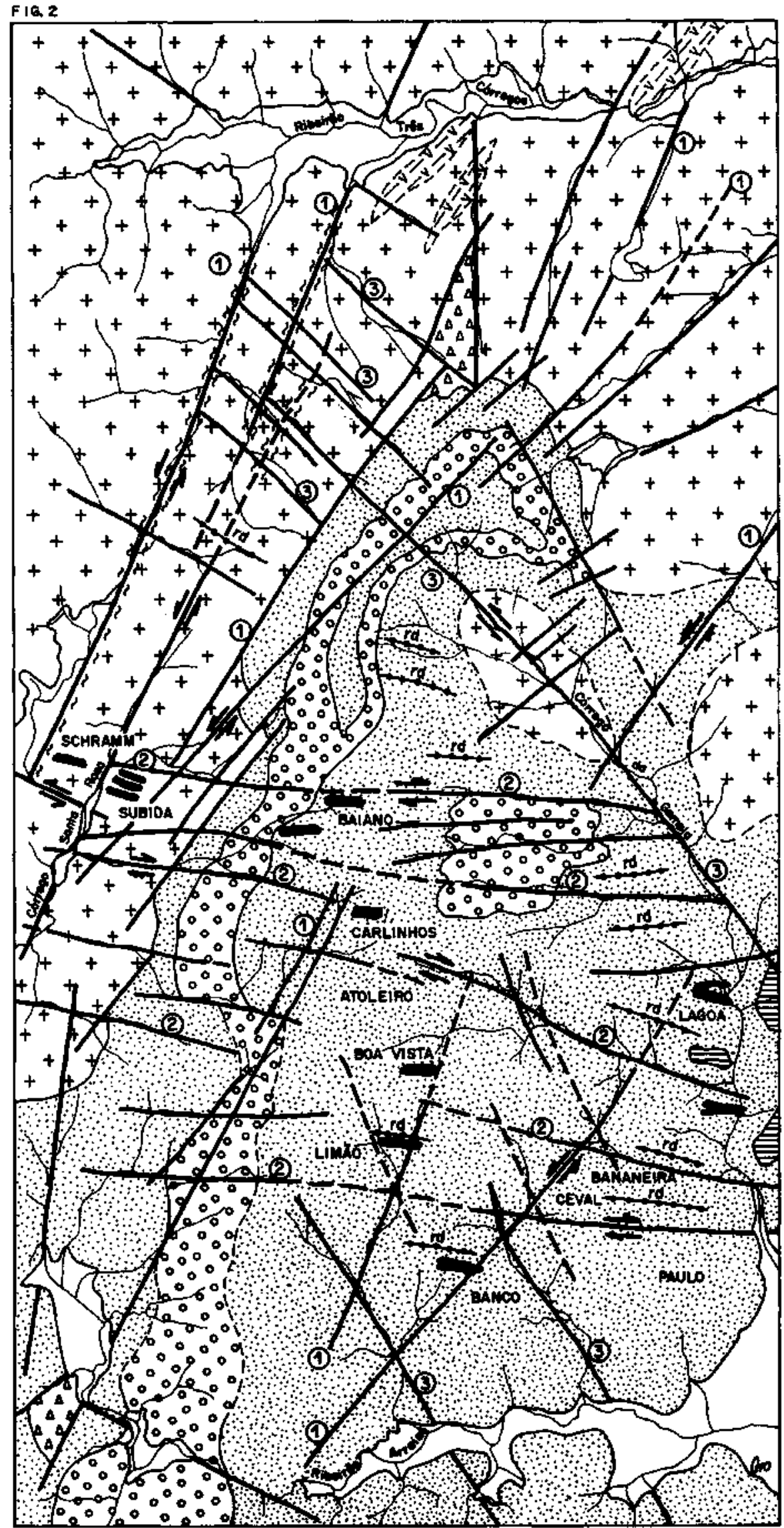

guntermán10

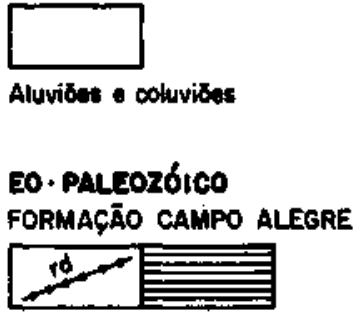

Diques do riodocitos (n) Argilitos 6 lomitoe. FORMACAO GASPAR \%००

Arenitos litoseldspáticos bordbs, proseseiros, interdigitados com conflomerodos Poll miticos do aramuleqöo e composicto woriodas Matriz arenítica.

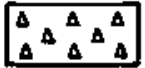

Erecha lifocládatica, prowovalmente aseocicdo aos folhamentos iniciats da bacio.

\section{AROUEANO \\ COMPLEXO LUIS ALVES

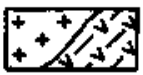

Embosomento de roches de fbcies granutitico, intensomanto follados in cortos locois, formando blostomilonitos e filonitos:

Formopose ferríferas, quartziwh, tc..., com metowes do anfibolitos anortoaitos.

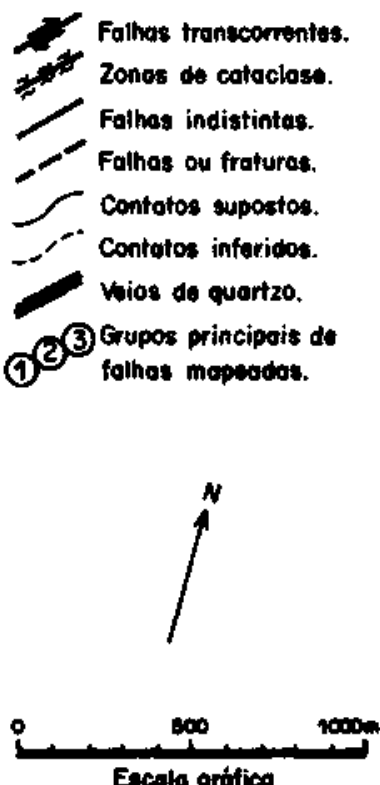

Eecolo ontifico

Figura 2 - Mapa geológico da área da Minepar, destacando a localização dos veios de quartzo auríferos (Projeto Arraial) Figure 2 - Local geological map of the Minepar area, detaching the quartz gold veins (Arraial prospect) 


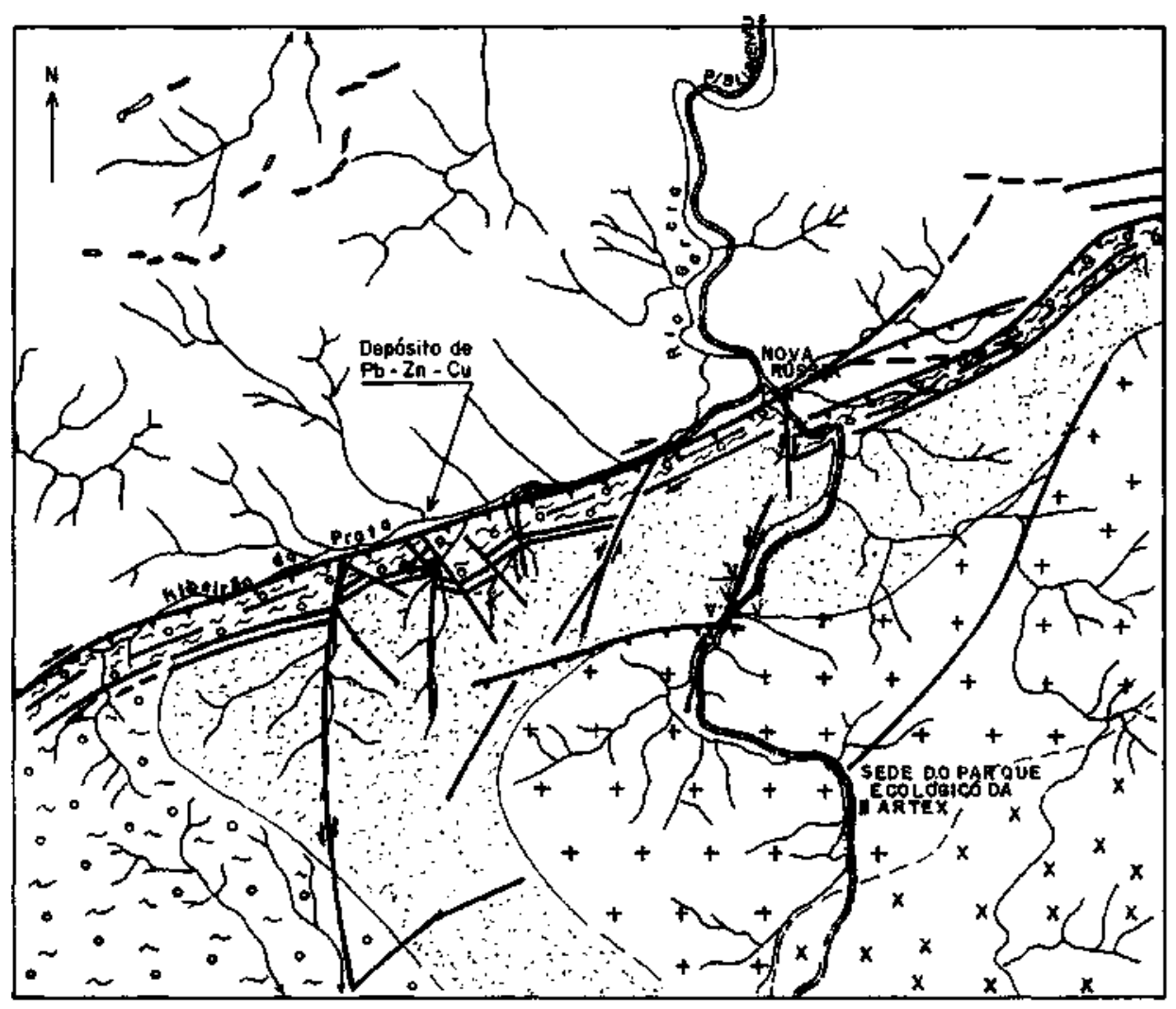

LEGENOA

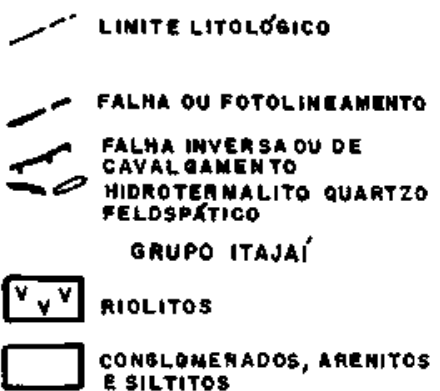

COMPLEXO TABOLEIRO

IFAIXA FIBEIRAOQWhATA

- XISTOS, WILONITOS

QMAISSES

HORWBLEMDA OHAISSE

ERAMITOS RdSEOS(ANATEXIA)

DIOAITOS CINZEHTOS

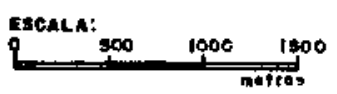

Figura 3 - Mapa fotogeológico (preliminar) da região do depósito do Ribeirão da Prata (Faixa Ribeirão da PrataComplexo Taboleiro)

Figure 3 - Preliminary photogeological map of Ribeirão da Prata mine regions (Ribeirão da Prata zone, Taboleiro complex)

são deslocadas por falhas transcorrentes dextrais orientadas E-W e por transcorrências menores, sinistrais, orientadas N5-30E(Fig.3).

No local da mina, a faixa Ribeirão da Prata é composta por homblenda gnaisses, gnaisses micáceos, granitos foliados e xistos entremeados por granitos róseos, aparentemente autóctones e anatéticos, e dioritos cinzentos (Basei 1985). Estas rochas mostram, com freqüência, zonas bastante hidrotermalizadas, identificadas pela presença de ventilações de propilita. Não são raros os domos e diques riolíticos em meio aos gnaisses e granitos, estruturas essas, provavelmente formadas durante o magmatismo da Formação Campo Alegre. A zona mineralizada do depósito do Ribeirão da Prata (Fig. 3) tem cerca de 20-30 m de espessura e 250-300 m de comprimento. Situa-se em meio aos milonitos e cataclasitos da falha do Perimbó, fazendo contato, a sul, com gnaisses a hornblenda. O minério é uma rocha hidrotermal de composição quartzo-feldspática.

MINERALIZAÇÕES ASSOCIADAS OUro em veios de quartzo (Minepar) VEIOS DE QUARTZO DO EMBASAMENTO No embasamento, foram localizados somente dois conjuntos de veios de quartzo, denominados Schramm e Subida. Embora menos numerosos, estes veios são maiores e mais mineralizados, contendo a maior parte das reservas de ouro primário conhecidas na região.

$\mathrm{O}$ veio de Schramm é o maior de toda a região: tem cerca de $600 \mathrm{~m}$ de comprimento e espessura variada entre $5 \mathrm{~cm}$ e $1 \mathrm{~m}$, foi reconhecido até $90 \mathrm{~m}$ da superfície, e aflora em parte encaixado por rochas subvulcânicas riodacíticas que cortam milonitos quartzo feldspáticos e quartzitos ferruginosos (Fig. 4) do embasamento granulitico. No geral, está encaixado em uma falha que atravessa granulitos foliados e gnaisses com atitude geral N50-60W, 65SW a subvertical. Para leste deste veio ramifica- se em uma profusão de filonetes com espessuras variadas entre $1 \mathrm{~cm}$ e $50 \mathrm{~cm}$ que ocupam uma área denominada Subida (Fig. 2), com cerca de $10 \mathrm{~m}$ de largura, quase no contato com o Grupo Itajaí.

Em superfície, o filão de quartzo está oxidado (fase Q, Fig. 4), tem quartzo de cores brancas e rosadas, e é rico em "box-works" preenchidos por óxidos de ferro e manganês pulverulentos. Em alguns locais há concentrações de argilas e de limonita. Drusas atapetadas por quartzo piramidado e estruturas em cocard sugerem um preenchimento em ambiente extensional.

Os contatos imediatos do veio de quartzo são hidrotermalizados, sobretudo argilizados, mas também propilitizados e feldspatizados. Tanto o gnaisse quanto a rocha ígnea estão silicificados e limonitizados, mostrando cores amarelo-esverdeadas. Apesar da argilização, a pirita é visível localmente.

$\mathrm{O}$ ouro foi detectado livre, quando no quartzo oxidado, ou associado à pirita e à calcopirita. Os teores de ouro são relativamente altos , variando entre 4 e $35 \mathrm{~g} /$ ton, com média de $10,2 \mathrm{~g} /$ ton. Os teores de prata variam entre 2 e $36 \mathrm{~g} /$ ton com média de 9,2 g/ton. A parte oxidada teria cerca de $12 \mathrm{~kg}$ de $\mathrm{Au}$ e $11 \mathrm{~kg}$ de Ag. Estima-se para o veio do Schramm uma reserva total de cerca de $100 \mathrm{~kg}$ de $\mathrm{Au}$.

As encaixantes hidrotermalizadas não contêm ouro ou o contém em teores muito baixos, menores que $1 \mathrm{~g} /$ ton. A parte hidrotermalizada do extremo leste do veio, na Subida, não mostrou reservas significativas

VEIOS DE QUARTZO NAS ROCHAS DO GRUPO ITAJAÍ Carlinhos, Baiano, Atoleiro, Boa Vista, Limo, Banco e Lagoa são locais sobre a Formação Gaspar onde foram identificados veios de quartzo com ouro (Fig. 2). Normalmente em cada um desses locais afloram conjuntos de veios paralelos formando uma zona ou faixa mineralizada (Fig. 5). Cada 


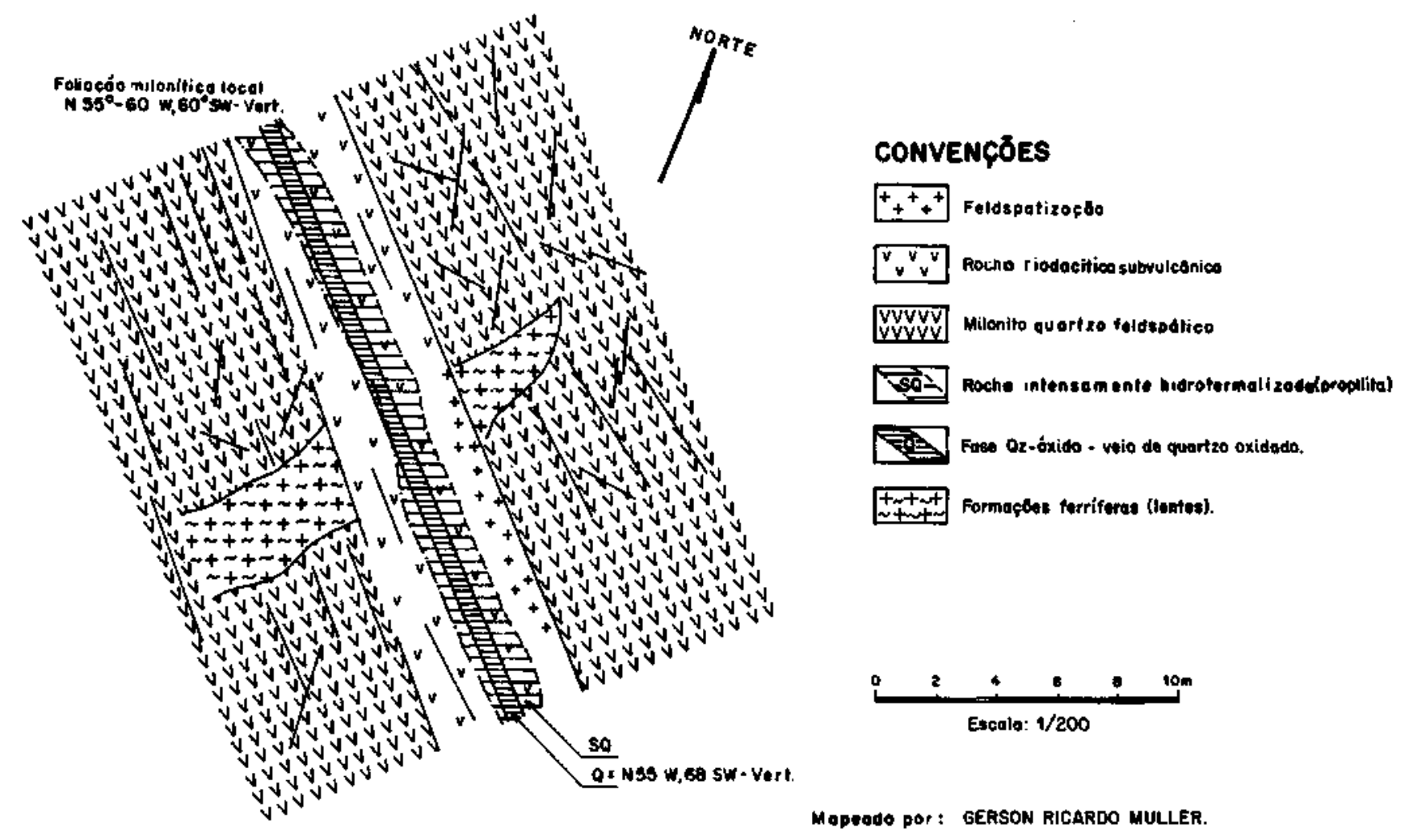

Figura 4 - Veio do Schramm - Mapa geológico parcial detalhado Figure 4 - Schramm gold vein detail partial geological map

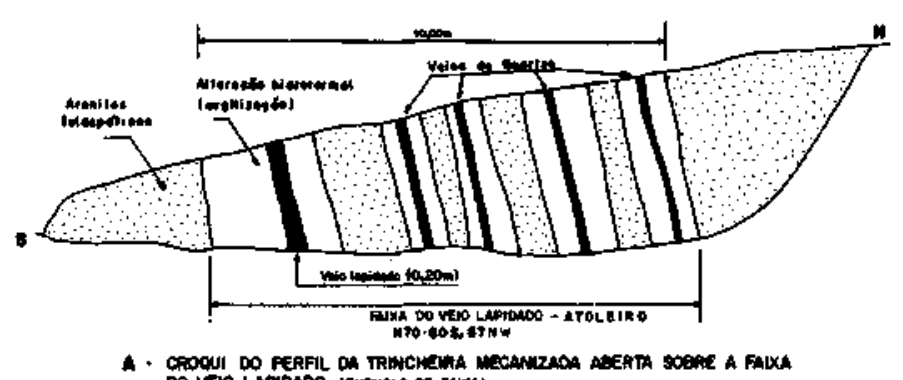

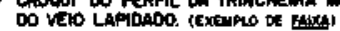

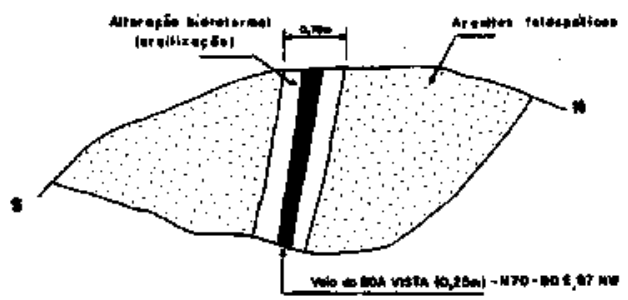

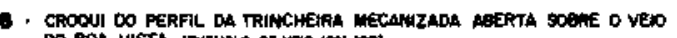

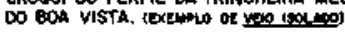

Figura 5 - Veios Atoleiro ou Lapidado (A) e Boa Vista (B) seções orientadas $\mathrm{N}-\mathrm{S}$

Figure 5 - Atoleiro or Lapidado (A) and Boa Vista (B) gold veins - N-S sections

veio de quartzo individualmente tem largura entre 5 e $50 \mathrm{~cm}$, e é bordejado por uma zona hidrotermalizada, argilizada e/ou silicificada, de largura variada, dependente da porosidade da rocha encaixante.

No total, estes conjuntos de veio de quartzo mais zonas hidrotermalizadas podem ter larguras entre 10 e $20 \mathrm{~m}$. O quartzo é branco, maciço ou brechado, com manchas cor ocre geradas pela oxidação da pirita. As encaixantes hidrotermalizadas são endurecidas pela silicificação e coloridas de marrom devido à presença de óxidos de ferro e manganês. Uma ocorrência curiosa, observada entre arenitos feldspáticos, é o veio do Limão (Fig. 2 e 6). No Limão, os veios de quartzo ocuparam os contatos de um dique de riodacito com a proximadamente 2,5 $\mathrm{m}$ de espessura. Tanto o riodacito quanto os arenitos esto hidrotermalizados. A rocha vulcânica mostra evidências de propilitização e silicificação. Os arenitos estão silicificados. Ambas as encaixantes têm manchas e filonetes de óxidos de ferro e manganês (Fig. 6). Nos veios de quartzo o único sulfeto visível, em pequena quantidade, é a pirita.

Os teores médios de Au dos veios de quartzo que afloram em meio aos sedimentos raramente são maiores que $1,0 \mathrm{~g} / \mathrm{ton}$. Pontualmente atingem 4,5 g/ton, em amostras de mão. Os teores médios de $\mathrm{Ag}$ não ultrapassam $5 \mathrm{~g} /$ ton. As encaixantes hidrotermalizadas têm teores de $\mathrm{Au}$ e $\mathrm{Ag}$ abaixo de $0,05 \mathrm{~g} /$ ton.

$\mathrm{O}$ veio do Limão foi o único, entre os sedimentos, que mostrou teores econômicos. O teor médio de Au medido no Limão foi de 4,7 g/ton. A reserva local foi estimada em 16,6 kg de Au.

Em geral os veios de quartzo do Arraial têm teores elevados de cobre e bismuto. O bismuto, particularmente nos veios encaixados por sedimentos, ocorre no quartzo em teores variados entre 500 e $3.000 \mathrm{ppm}$. Nos veios do embasamento os teores são inexpressivos. O cobre atinge $2.700 \mathrm{ppm}$ em alguns veios, embora na média os teores estejam abaixo de $500 \mathrm{ppm}$. O chumbo, com teores entre 50 e 400 ppm, está, também, presente nos veios de quartzo da região.

Tanto o veio de quartzo do Schramm (Fig. 4), no embasamento, quanto o do Limão (Fig. 6), nos sedimentos, mostram relações diretas com diques riodacíticos. Estas relações indicam que a mineralização é posterior ao vulcanismo, dado que o hidrotermalismo e a mineralização afetam as rochas vulcânicas. É bem possível que os veios de quartzo se tenham 
VISTA EM PLANTA

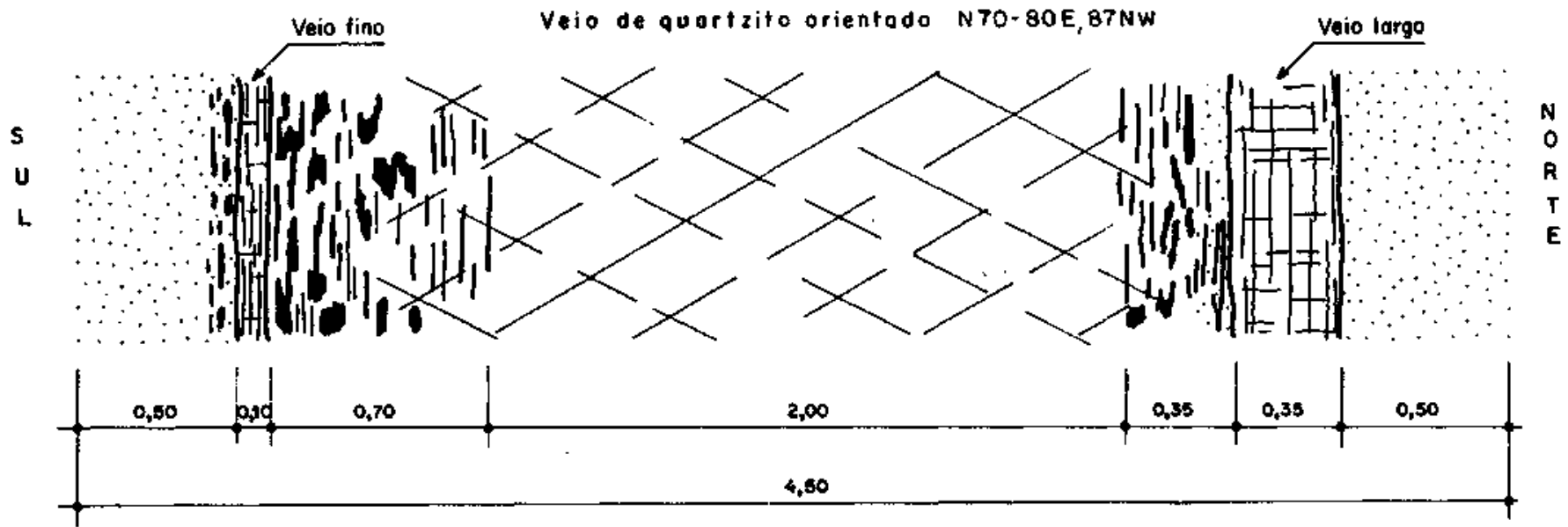

Obs.: Medides em metros

\section{CONVENÇŌES}

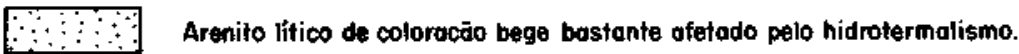

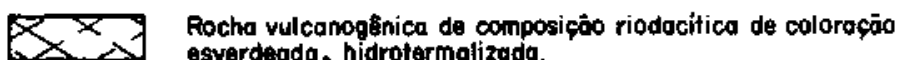

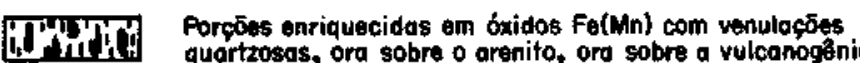

事] Veio de quartzo com b́xidos Fe sulfetos.

Figura 6 - Veio do Limäo - vista parcial em planta

Figure 6 - Limso gold vein - parial map view

formado ao final da época Campo Alegre ( $541 \pm 26 \mathrm{Ma})$ como conseqüência deste vulcanismo.

\section{Chumbo, cobre e zinco do Ribeirão da Prata $\mathrm{O}$} minério do depósito do Ribeirão da Prata é um hidrotermalito quartzo-feldspático de cor esbranquiçada ou cinza-rosada, muito duro, maciço e estruturahnente isótropo. A mineralização é toda sulfetada e ocorre disseminada no hidrotermalito, concentrando-se em locais onde esta rocha é venulada por quartzo. Galena, calcopirita, pinta e esfalerita são os principais sulfetos. Calcocita, covellina e bornita ocorrem subordinadamente. Oxidos de ferro e manganês são comuns. Sulfatos e carbonates $\mathrm{de} \mathrm{Pb}, \mathrm{Zn}$ e Cu são, também, comuns nas zonas percoladas por águas meteóricas.

A zona mineralizada tem de 20 a $30 \mathrm{~m}$ de largura. Aflora em meio a milonitos da falha do Perimbó e é limitada, a sul, por gnaisses com homblenda portadores de uma foliação marcante, paralela aos contatos (Figs. 7 e 8). A mineralização termina lateralmente de modo gradativo. A pesquisa, no local do depósito foi feita por galerias abertas em três níveis (galeria $\mathrm{A}$ na quota, $235,6 \mathrm{~m}$, galeria $\mathrm{B}$ na quota $228,1 \mathrm{~m}$ e galeria $\mathrm{C}$ na quota 207,8 m - Fig. 7). Os teores são maiores nos níveis superiores, situados, provavelmente, em zona de cimentação supergênica.

O limite sul da zona mineralizada (Fig. 8) é nítido, bem marcado por uma falha (F $4=\mathrm{E}-\mathrm{W}, 73 \mathrm{~S})$ associada a planos com atitudes iguais às da falha do Perimbó (N6070E,60-70SE). O limite norte é menos preciso. E, também, nítido, porém bastante segmentado por falhas de baixo ângulo, abertas, preenchidas por material pulverulento cimentado por argilominerais e por óxidos de ferro e manganês. Estas falhas têm mergulhos de 20 a 30 graus para norte, com rejeitos diretos de 1 a 5 metros (Fig. 8). Estes rejeitos não segmentam o contato sul.

O contato dos milonitos quartzo-feldspáticos, que encaixam a mineralização, com os conglomerados do Itajaí faz-se através de uma falha reversa. Este contato aflora a poucos metros da margem do Ribeirão da Prata, em frente às galerias (Figs. 7 e 8).

CONTROLE ESTRUTURAL DAS MINERALIZAÇÕES Controle estrutural dos veios de quartzo com ouro (Minepar) Nesta região foram medidas e descritas fraturas em afloramentos nas galerias de pesquisa feitas no embasamento e junto aos veios de quartzo do Grupo Itajaí. Amedida das estrias de falhas, a identificação de degraus, adeterminação do sentido de deslocamento dos blocos de falhase $o$ tipo de preenchimento ou ausência de preenchimento dos planos de falhas e juntas foram auxiliares importantes na determinação dos sistemas conjugados de falhas existentes na região.

A principal orientação determinada nas rochas do embasamento é a de uma foliação gnáissica com atitude média N26W.86NE (Fig. 9). Como será mostrado, esta foliação no foi posteriormente transformada em superficie de quebramento. A sua atitude não coincide com nenhuma das atitudes de falhas ou de juntas medidas na região do Arraial. As figuras 10, 11, $12,13,14,15,16$, e 17 mostram as principais modas de fraturas e lineações observadas na área da Minepar, no embasamento (Figs. 10, 11 e 12) e nas rochas sedimentares (Figs. 13, $14,15,16$ e 17). Alguns comentários devem ser feitos visando embasar as soluções a serem propostas para explicar os sistemas de fraturas observados nessa área. 


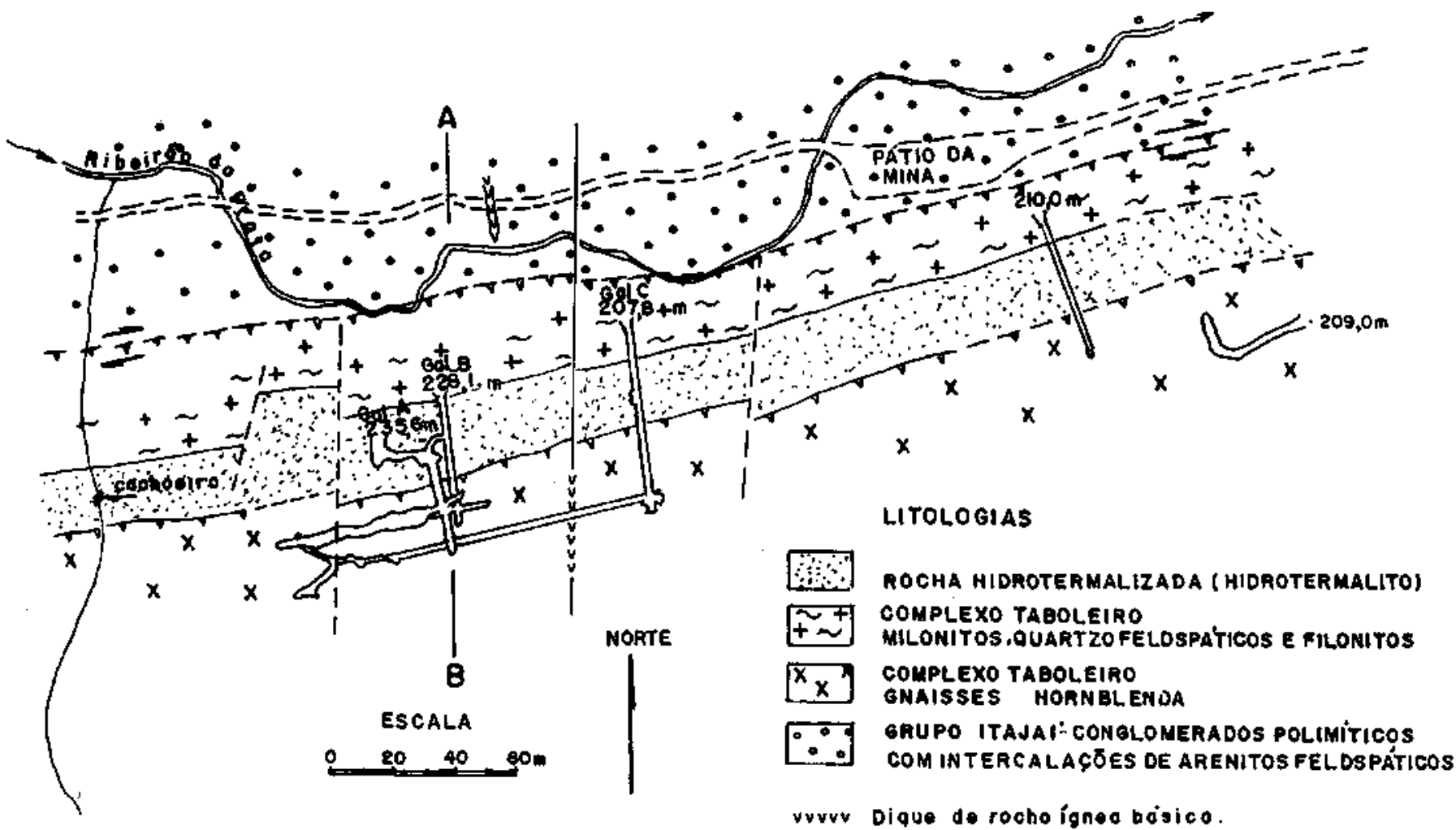

Figura 7 - Mapa geológico de detalhe do depósito de Pb-Cu-Zn do Ribeirão da Prata

Figure 7 - Local geological map of Ribeirão da Prata $\mathrm{Pb}-\mathrm{Cu}-\mathrm{Zn}$ deposit

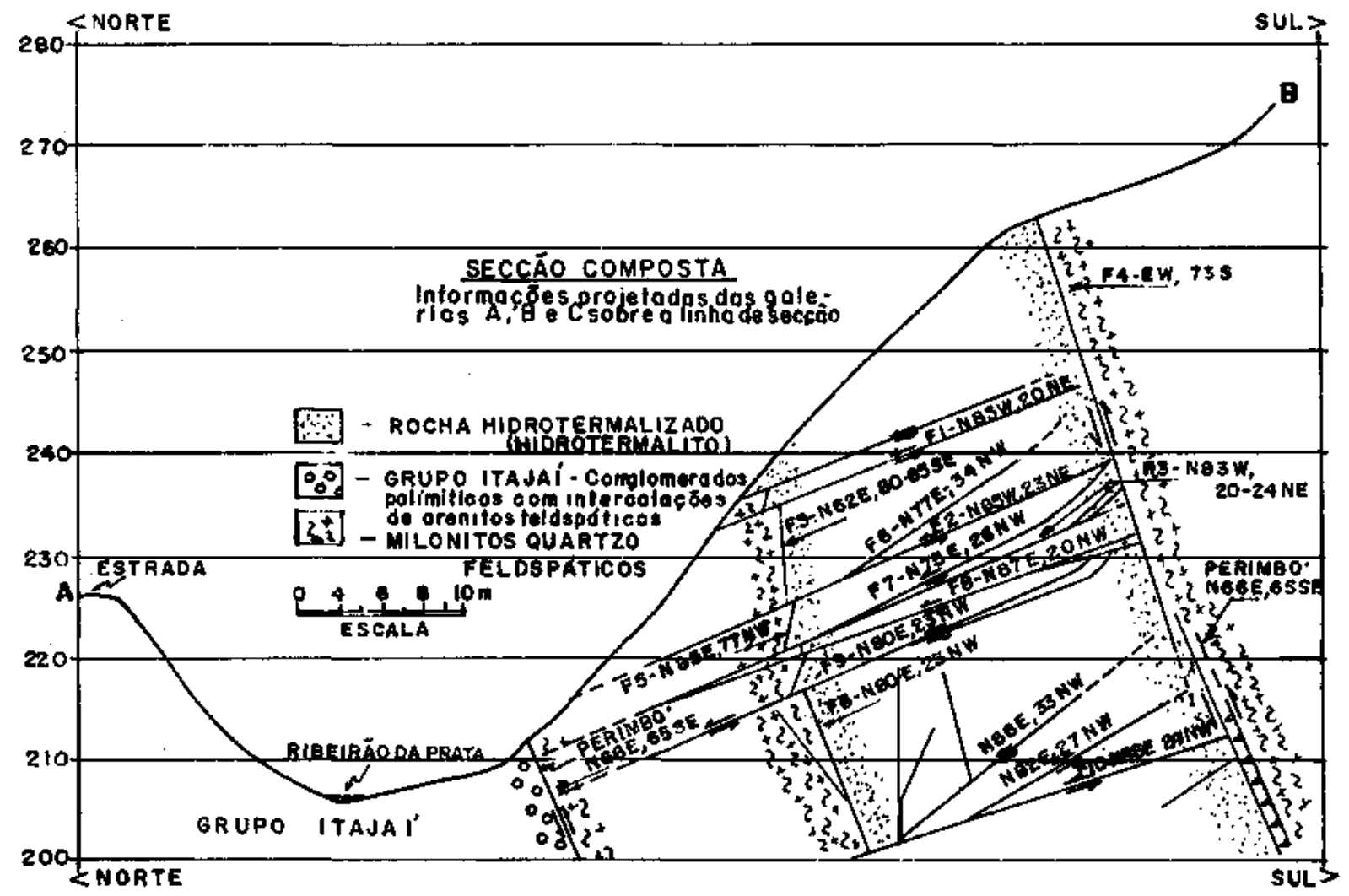

Figura 8 - Seção $\mathrm{N}-\mathrm{S}$ sobre o depósito de Pb-Cu-Zn do Ribeirão da Prata

Figure 8 - N-S section crossing the Ribeirão da Prata $\mathrm{Pb}-\mathrm{Cu}-\mathrm{Zn}$ deposit 
Conforme já comentado, as falhas do grupo 1 são transcorrências sinistrais. A presença de cataclasitos em alguns locais, em meio a milonitos, sugerem que sejam antigas faixas milonitizadas reativadas em regime dúctil. Na cobertura sedimentar estas falhas ocorrem sem preenchimento (moda U, Fig.16), o que permite diferenciá-las da moda R (Fig. 15), muito próxima, sem preenchimento. A presença de lineações minerais horizontalizadas e de degraus (raros) indicam que as fraturas R são também transcorrências sinistrais.

As falhas do grupo 2 (Fig. 2) são paralelas aos diques e algumas vezes encaixam os diques de riodacito e ríolito da

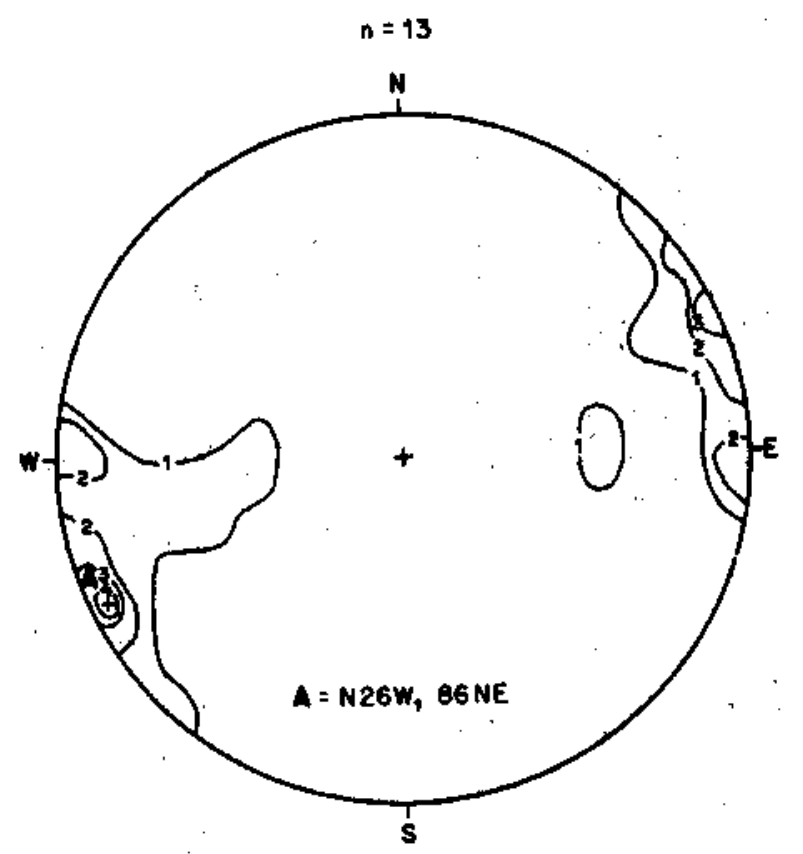

Figura 9-Embasamento (foliações)

Figure 9 - Basement foliation

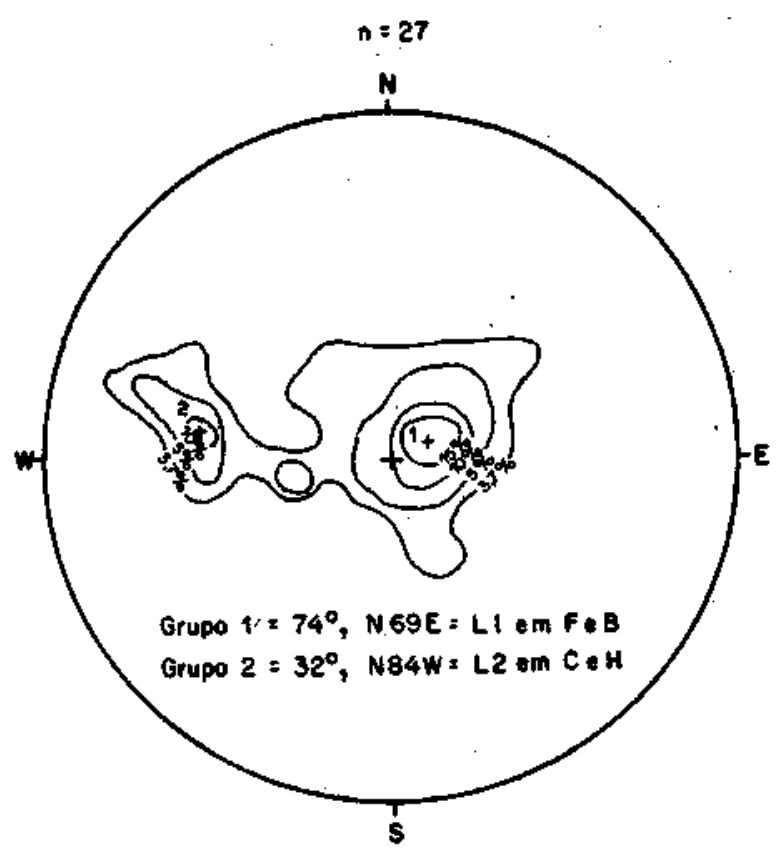

Figura 10 - Lineações das fraturas das galerias do Schramm Figure 10 - Lineations in fractures from Schramm galleries região. Os 44 veios de quartzo auríferos identificados em meio aos sedimentos do Itajaí preenchem estruturas com a mesma orientação dessas falhas (moda Q, Fig. 14, e modas K e I, Fig. 12). Todas estas evidências indicam terem sido estruturas extensionais, abertas. Entretanto, em alguns planos com esta direção foram observadas, também, lineações de fibras minerais com degraus que indicam que estas fraturas tiveram movimentos horizontais dextrais (planas a norte dos veios da Subida e do Baiano, Fig. 2).

De interpretação complexa são também as fraturas do grupo 3 (Fig. 2, modas B da Fig. 11 e da Fig. 12). Os veios do

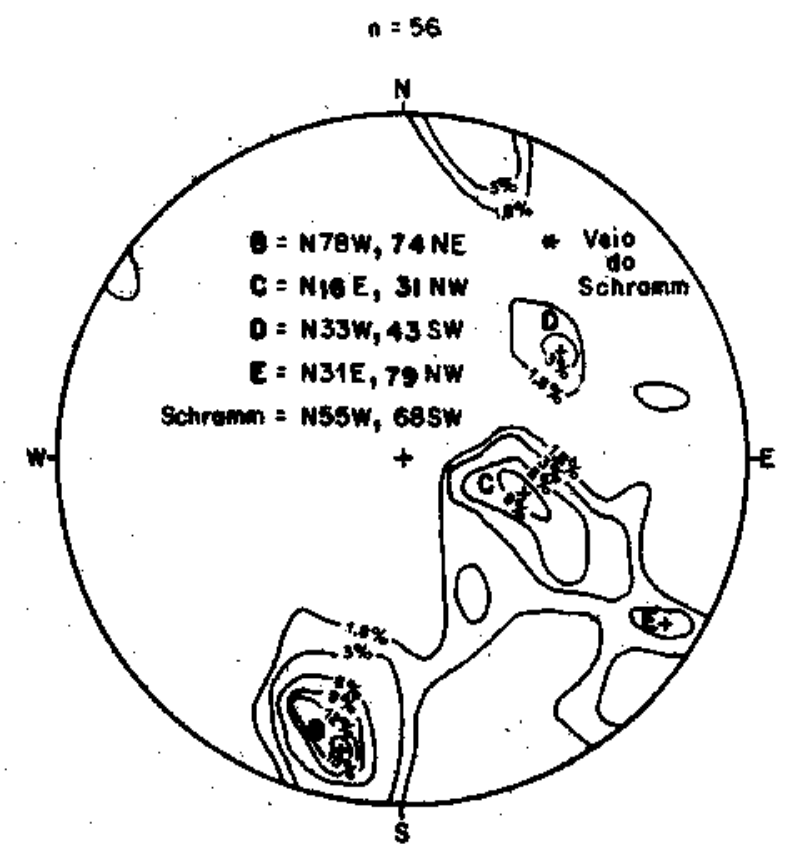

Figura 11 - Fraturas da galeria 3 do Schramm Figure 11 - Fractures from Gallery n 3 - Schramm vein

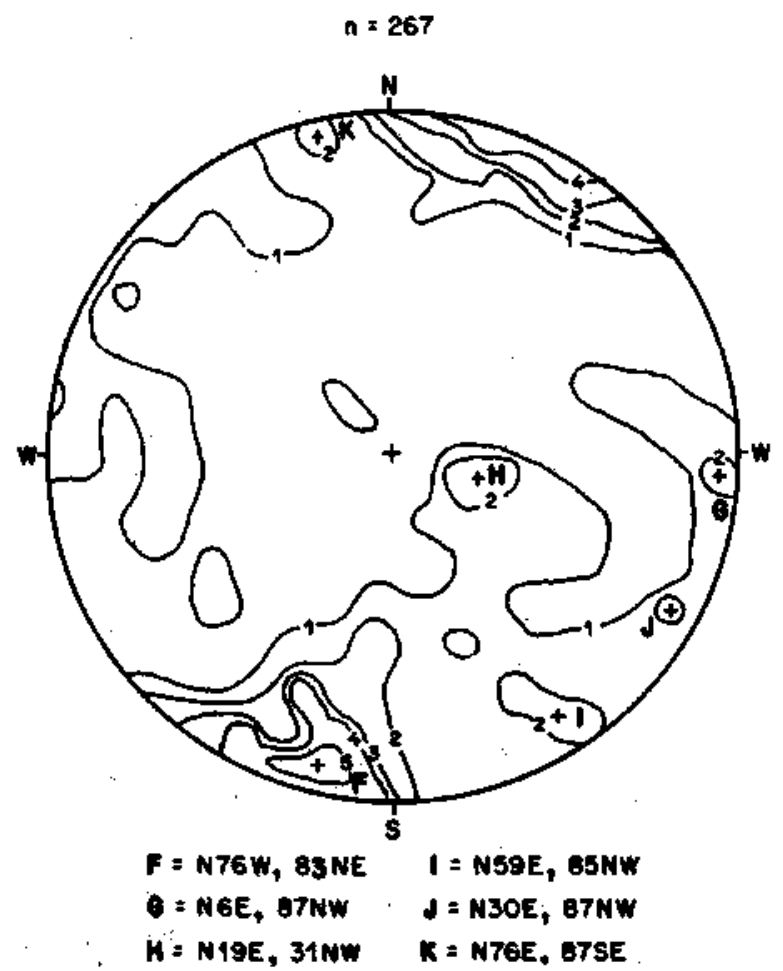

Figura 12 - Fraturas do embasamento Figure 12 - Basement fractures 


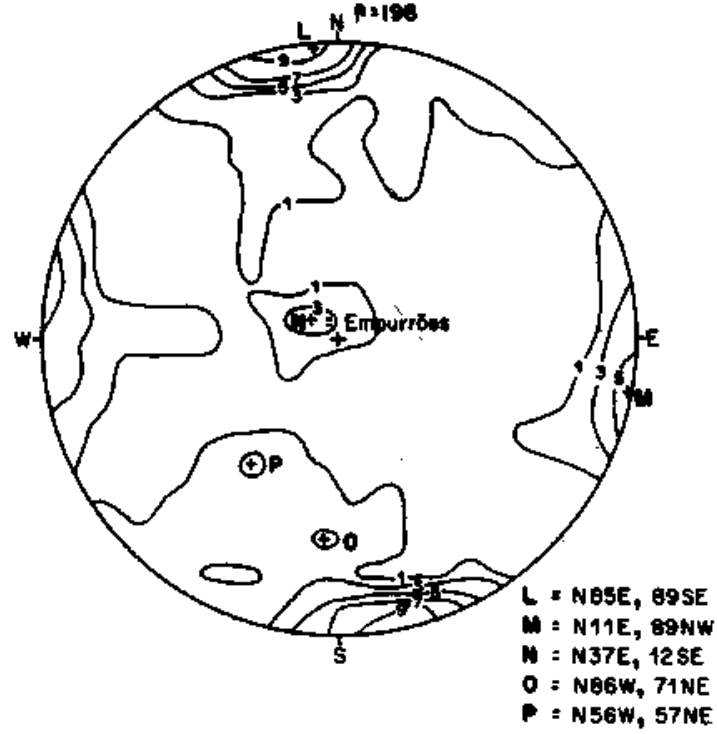

Figura 13 - Fraturas do Grupo Itajai Figure 13 - Itajaí group fractures

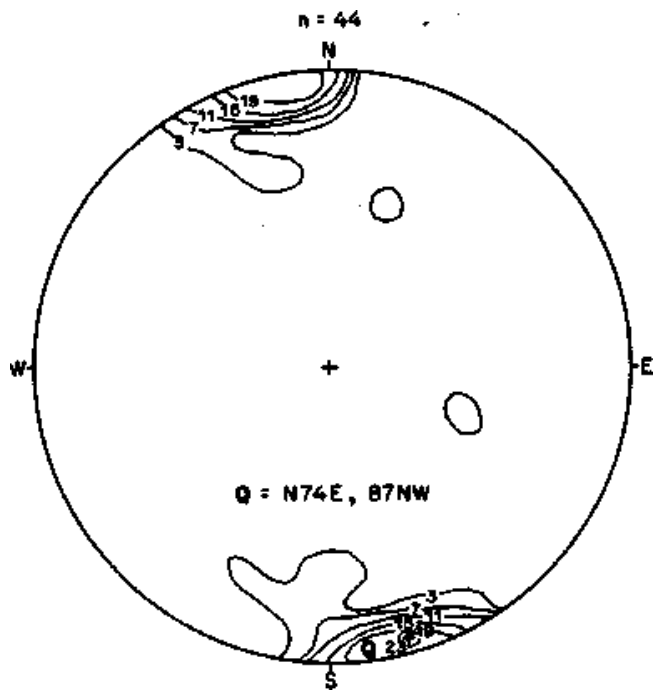

Figura 14 - Veios de quartzo do Grupo Itajaí Figure 14 - Quartz veins from Itajaí group

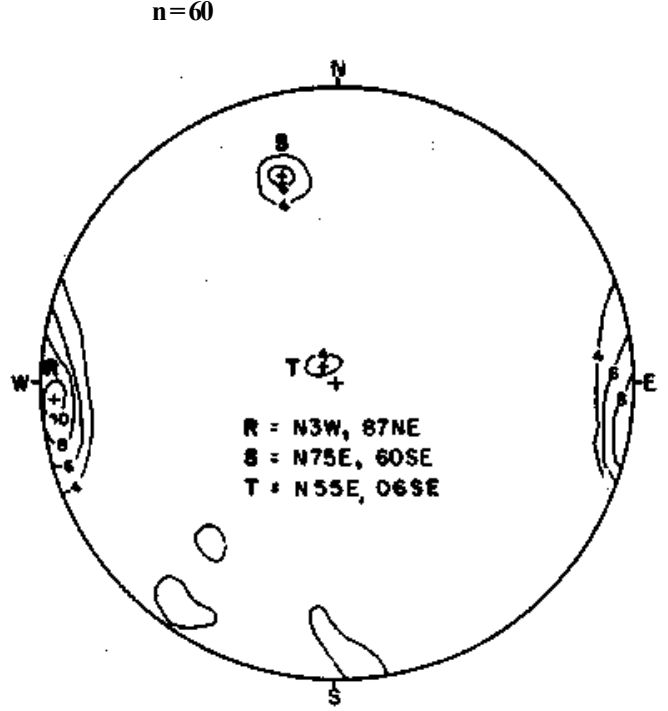

Figura 15 - Grupo Itajaí. Fratura com $\mathrm{Fe}, \mathrm{Fe}+\mathrm{Mn}$ e $\mathrm{Mn}$ Figure 15 - Fractures with $\mathrm{Fe}, \mathrm{Fe}+\mathrm{Mn}$ e Mn - Itajaí group

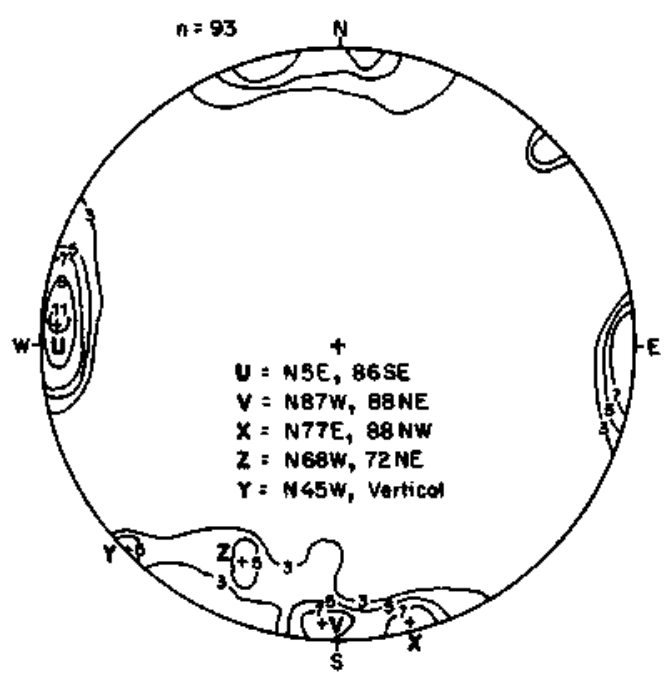

Figura 16 - Grupo Itajaí. Fraturas sem preenchimento Figure 16 - Not filled fractures - Itajaí group

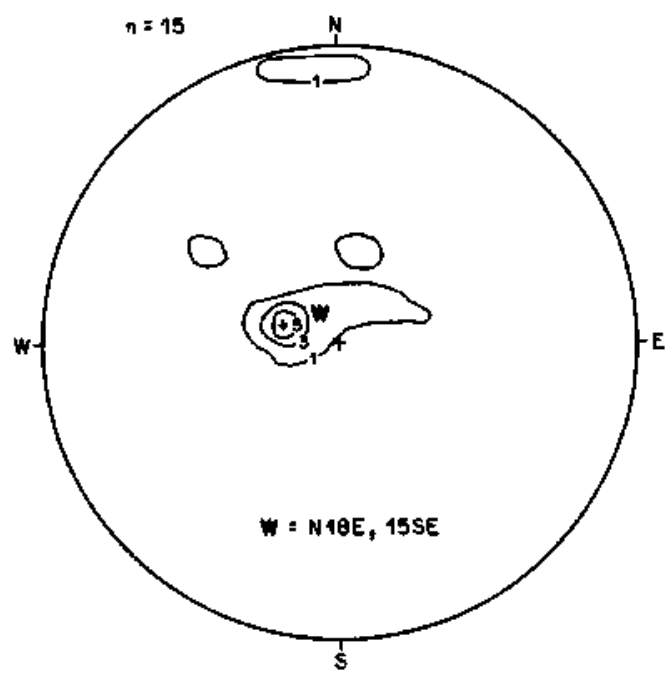

Figura 17 - Grupo Itajaí. Falhas de baixo ângulo, com gouge

Figure 17 - Low angle fractures - Itajaí group 
FASE !

SINISTRAL COMPRESSIONAL (TAANSPRE\$SION)
FASE 2

DEXTAAL DISTENSIONAL

(TRANSTENSION)
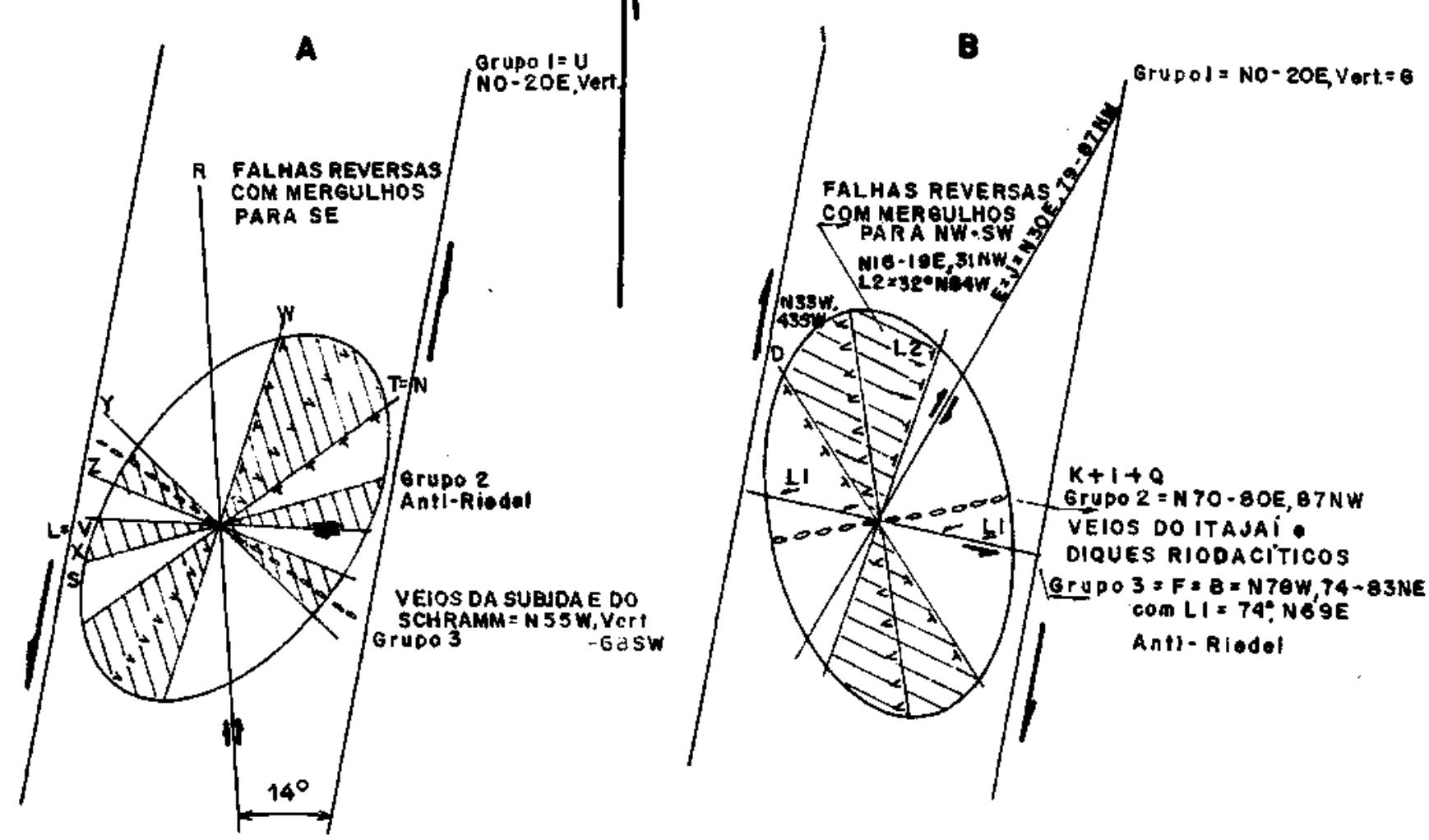

Figura 18 - Orientação das fraturas da região aurífera de Gaspar (área da Minepar -fig. 2). A. Primeira fase de deformação; B. última fase de deformação

Figure 18- Fracture orientations of the Minepar gold region (fig. 2). A. First deformation phase; B. Final deformation phase

Schramm e da Subida têm atitudes coincidentes com as dessas fraturas. As feições anteriormente descritas (Fig. 4) mostram que ao menos em uma fase da orogênese essas fraturas foram abertas, extensionais. Entretanto, na antiga galeria 3 do veio do Schramm (moda B, Fig. 11), estas falhas têm lineações, degraus e estrias com atitude de L1 (grupo 1, Fig. 10), indicando um movimento reverso, mergulho acima, com uma componente dextrógira.

São também importantes as falhas de baixo ângulo observadas no embasamento (modas $\mathrm{C}$ e $\mathrm{D}$, Fig. L $11 \mathrm{e}$ moda H, Fig. 12) e na cobertura sedimentar (moda N, Fig. 13, moda T, Fig. 15 e moda W, Fig. 17). Notar que no embasamento estas fraturas sempre têm mergulhos para NW-SW. As lineações L2 (grupo 2, Fig. 10) foram medidas nessas fraturas e, junto aos degraus, indicam um movimento reverso, com o blocoNW cavalgando o bloco SE. Na cobertura sedimentar, ao contráriodo embasamento, os mergulhos são sempre para SE. Não são falhas locais, secundárias, associadas a dobramentos e formadas por compressão paralela às camadas dobradas (deslizamentos inter e intra-estratais), dado que essas dobras nãoexistem na borda norte da bacia sedimentar do Itajaí.Aomenosas falhas correspondentes à moda W (Fig. 17) têm planos com pó de rocha (gouge), o que sugere um deslocamento com forte atrito. Há lineações que indicam que o principal deslocamento teve direção NW-SE. Infelizmente não foramencontrados indicadores cinemáticos que mostrassem o sentidodo deslocamento.

Finalmente, as modas E e J (Figs. 11 e 12), que foram descritas somente em afloramentos do embasamento. São fra- turas pouco comuns nas quais não foram observados indicadores cinemáticos conclusivos.

Considerar as falhas do grupo 1 (Fig. 2) como as principais transcorrências da área possibilitaria uma explicação para o sistema de fraturas descrito (Fig. 18 A e B). No início da deformação que afetou o Grupo Itajaí, teria ocorrido uma compressão de SE para NW (Basei 1985, Rostirolla 1991, entre outros) que reativaria as antigas falhas do embasamento. Inicialmente em regime transpressional (Fig. $18 \mathrm{~A}$ ), as falhas do grupo 1 gerariam sintéticas com moda R, antitéticas com moda igual à das falhas do grupo 2 , falhas reversas com modas $\mathrm{N}, \mathrm{T}$ eW e falhas extensionais com modas $\mathrm{Y}, \mathrm{Z}$ e iguais às falhas do grupo 3. Notar que nesta primeira fase da deformação somente o embasamento foi mineralizado (veios do Schramm e Subida, Fig. 18A), formando veios de quartzo com características distintas (alto teor de $\mathrm{Au}$ e baixo teor de $\mathrm{Bi}$ ) dos veios da cobertura sedimentar, conforme descrito anteriormente.

Uma explicação alternativa, aventada por Rostirolla (1991), seria considerar, nesta primeira fase da deformação, um sistema compressivo coaxial (cisalhamento puro), orientado de SE para NW. Este sistema poderia gerar o mesmo conjunto de fraturas descrito e seria uma explicação para o ângulo muito aberto $\left(90^{\circ}-100^{\circ}\right)$ formado entre as falhas sintéticas e antitéticas (Fig. $18 \mathrm{~A}$ ), entretanto não explicaria a reativação das falhas do grupo 1 com rejeitos horizontais.

Ao final da orogênese, o relaxamento do sistema permitiria a reverso localizada do movimento de algumas estruturas. Aparentemente a área da Minepar seria um desses locais. Em regime transtensional dextral (Fig. 18B) as mesmas falhas do 


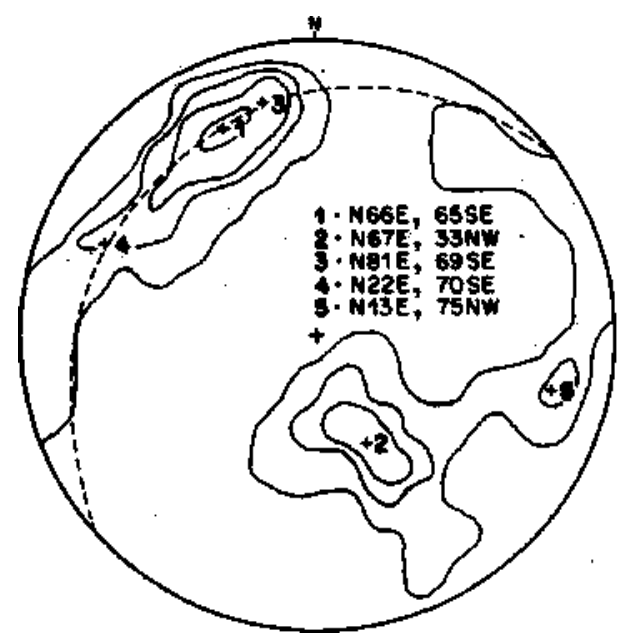

Figura 19 - Fraturas medidas nas galeria do depósito do Ribeirão da Prata $(n=348)$

Figure 19 - Fractures from galleries - Ribeirão da Prata deposit (n=348) -1,3, 5 e $10 \%$ contour lines

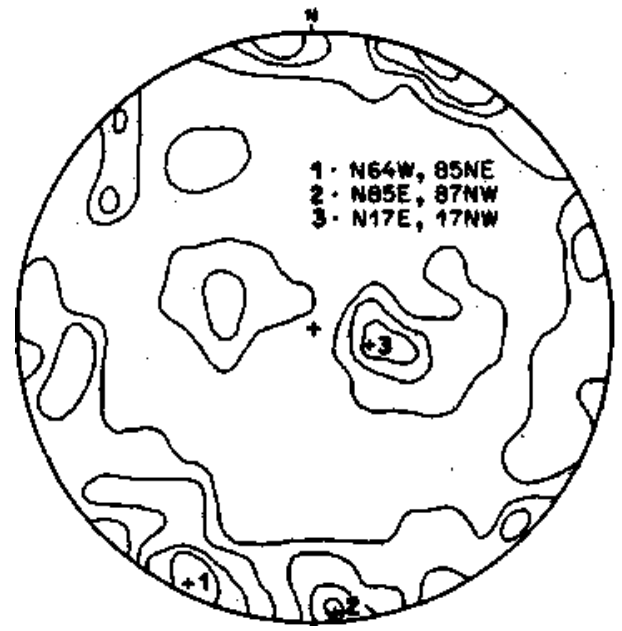

Figura 20 - Fraturas medidas nos hornblenda gnaisses (HG) da faixa do Ribeirão da Prata (Complexo Taboleiro),(n-131) Figure 20 - Fractures from horblende gneisses - Ribeirão da Prata region $(n=131)-1,3,5$ e $10 \%$ contour lines

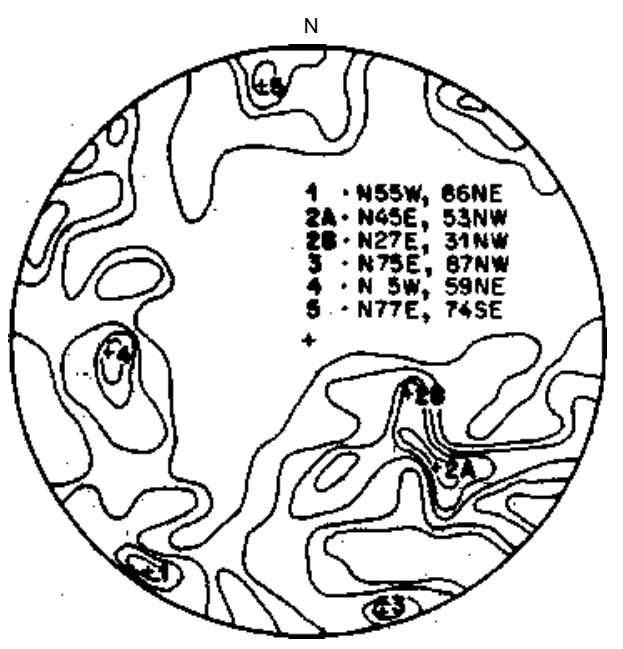

Figura 21 - Fraturas medidas nos granitos (y) róseos da faixa do Ribeirão da Prata (Complexo Taboleiro) $(n=70)$

Figure 21 - Fractures from pink granites - Ribeirão da Prata region $(\mathrm{n}=70)$ $1,2,4,5$ e $7 \%$ contour lines

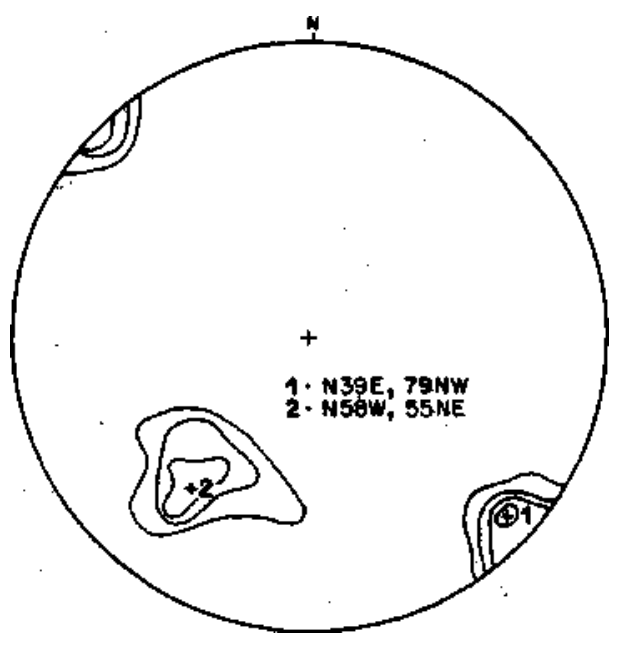

Figura 22 - Fraturas medidas nos granitos foliados e hidrotermalizados $(\gamma F)$ da faixa do Ribeirão da Prata (Complexo Taboleiro) $(n=24)$

Figure 22 - Fractures from hydrothermalized and foliated granites - Ribeirão da Prata region $(n=24)-1,3,5$ e $7 \%$ contour lines

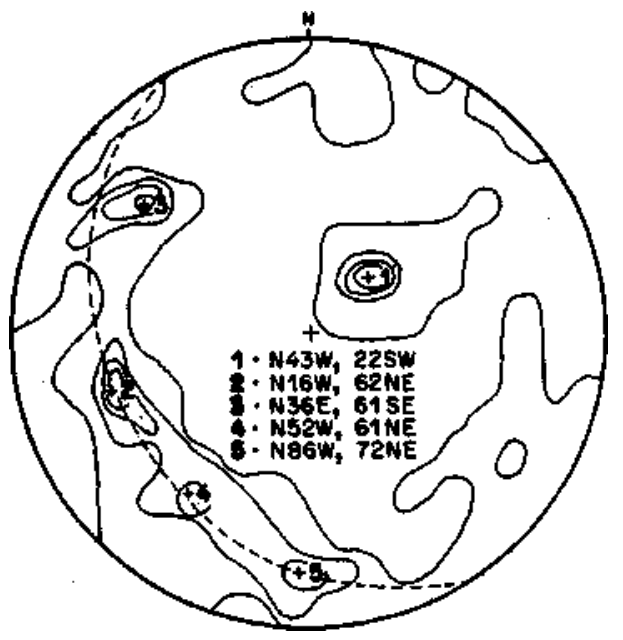

Figura 23 - Fraturas medidas nos riolitos da faixa do Ribeirão da Prata (Complexo Taboleiro) (n-141)

Figure 23 - Fractures from ryolites - Ribeirão da Prata region $(n=141)-1,3,4$, e $5 \%$ contour lines 
grupo 1 (Fig. 2), gerariam um sistema conjugado de fraturas onde as modas E e J seriam sintéticas (?), as falhas do grupo 3 seriam antitétícas, as fraturas D, C e H seriam compressionais e as modas Q, I e K seriam de fraturas extensionais. Nesta fase, transtensional, haveria um aporte maior de soluções hidrotermais que preencheriam as fraturas abertas, extensionais (modas Q, I e K) do sistema, gerando os 44 veios de quartzo localizados na região. As falhas do grupo 3 , abertas e mineralizadas na primeira fase, agora ocupariam posições antitétícas com forte deslocamento reverso, não sendo acessíveis aos novos fluidos hidrotermais silicosos. Infelizmente, este segundo hidrotermalismo, de muito maior volume que o da primeira fase da deformação, proporcionaria um aporte muito menor de ouro aos veios de quartzo. Rostirolla (1991) descreveu, também, várias estruturas no Grupo Itajaí onde foram observadas evidências da reversão dos rejeitos na última fase deformacional da orogênese Itajaí.

Controle estrutural das mineralizações $\mathrm{Pb}-\mathrm{Cu}-\mathrm{Zn}$ do Ribeirão da Prata Duas situações estruturais foram examinadas na faixa Ribeirão da Prata:

a) As estruturas do depósito de $\mathrm{Pb}-\mathrm{Cu}-\mathrm{Zn}$, descritas nas galerias e em afloramento na região mineralizada;

b) As estruturas das litologias regionais, próximas ao depósito.

\section{Estruturas do corpo mineralizado e encaixantes}

O corpo mineralizado do Ribeirão da Prata está dentro da zona de falha do Perimbó (Figs. 8, 9 e 19). O minério, estruturalmente isótropo (sem foliações ou lineações minerais), aparenta ser uma rocha hidrotermal formada após a nucleação da falha do Perimbó, preenchendo espaços e substituindo rochas existentes, na época, na zona de falha. Há vestígios de indicadores cinemáticos que sugerem que esta falha tenha inicialmente sido uma transcorrếncia. Após a formação do corpo mineralizado, que se deu provavelmente no início do magmatismo Campo Alegre, a falha do Perimbó foi reativada como falha reversa, durante a primeira fase de deformação do Grupo Itajaí (Fig. 18 A). O deslocamento reverso fez-se sobretudo segundo os planos antigos de cisalhamento (modas 1 e 3, Fig. 19) e gerou fraturas secundárias abertas (moda 2 da Fig. 19 e fraturas debaixo ângulo de Fig. 8) que segmentaram os contatos do corpo mineralizado. O contato norte do corpo mineralizado tomou-se uma zona de fortes deslocamentos reversos que destruíram os rejeitos (denteações) gerados anteriormente naquele local. O contato sul foi pre-servado desses deslocamentos, ocorridos, desse lado, no contato com o Itajá (Figs. 07 e 08), e é, atualmente, muito segmentado pelos deslocamentos secundários de baixo ângulo.

Estruturas das litologias regionais, próximas ao depósito Os estereogramas das figuras $20,21,22$ e 23 foram feitos com medidas de fraturas de rochas aflorantes na faixa Ribeirão da Prata (Complexo Taboleiro) próximo ao depósito homônimo. As fraturas medidas nos gnaisses (Fig.20), nos granites rosados (Fig. 21) e nos granitos tódroterrnalizados (Fig.22) podem ser interpretadas como per-tencentes a um único sistema conjugado de fraturas (Fig. $24 \mathrm{~A}$ ) formado em função da falha do Perimbó. Se, como foi discutido anteriormente (Fig. $18 \mathrm{~A}$ ), considera-se um movimento inicial compressivo de SE para NW no começo da deformação Itajái, a falha do Perimbó seria reativada como falha reversa com uma componente de rejeito horizontal dextral (Fig. 24 A). Este sistema, também adotado por Rostirolla (1991) para o Grupo Itajá, geraria fraturas de baixo ângulo, com estrias orientadas NW-SE, correspondentes às das modas $\gamma 2 \mathrm{~A}$ e $\gamma 2 \mathrm{~B}$ (Fig. 21), $\mathrm{HG} 3$ (Fig. 20) e y Fl (Fig. 22). As modas de $\gamma 3$ e de $\gamma 5$ (Fig. 21) e de HG 2 (Fig. 20)corresponderiam a sinteticas e a moda $\gamma$ 4 (Fig. 21) e 4+5 (Fig. 19) a antitéticas. Estrias e degraus (raros) observados nas galerias confirmam estes rejeitos. Finalmente, as modas HG 1 (Fig. 20), $\gamma 1$ (Fig. 21) e $\gamma$ F 2 (Fig. 22) seriam

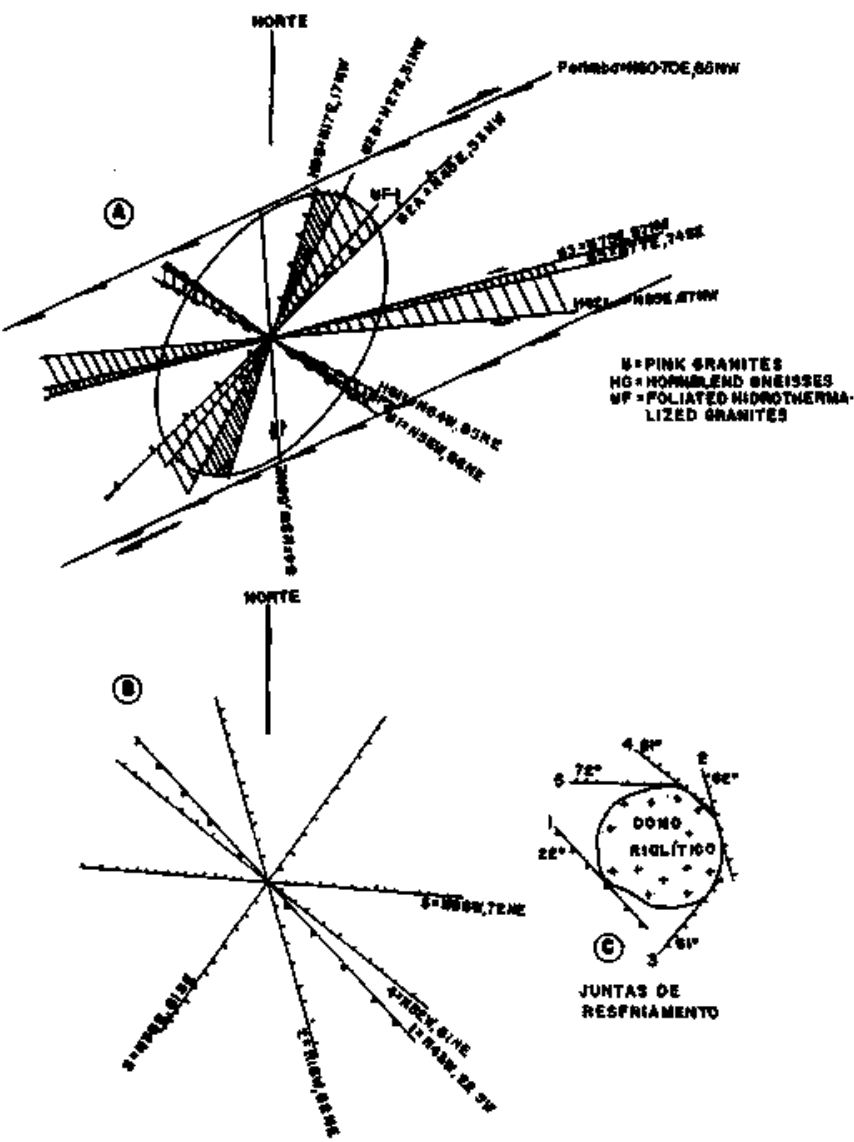

Figura 24 - Orientação das fraturas da região do Ribeirão da Prata (Figs. 03 e 07). A. fraturas medidas regionalmente; B. orientação das fraturas medidas nos riolitos; C. esquema mostrando a organização das fraturas no domo ríolítico Figure 24 - Fracture orientations of Ribeirão da Prata regions. A. first deformation phase; B. fractures orientation of ryolites; C. scheme showing the organization of fractures of fratures of ryolitic domes

de fraturas extensionais. Feições plumosas observadas nos granitos e o preenchimento hidrotermal (propilitização) nos granitos foliados sugerem que estas fraturas sejam abertas, conforme indicado pela geometria proposta na Fig. $24 \mathrm{~A}$.

Os riolitos (Figs. 23 e $24 \mathrm{~B}$ e C) portam um sistema de fraturas muito diferente daquelas das outras rochas da faixa Ribeirão da Prata. As características de afloramento, com feições plumosas e a ausência de micro rejeitos, além da geometria do conjunto, sugerem que estas fraturas tenham sido geradas pelo resfriamento do domo riolíitico (Fig. 24 C). Se esta interpretação for correta, as intrusões riolíticas teriam ocorrido após cessados os esforços que deformaram todas as outras rochas, da faixa Ribeirão da Prata e do Grupo Itajaí, encontrando a mineralização de $\mathrm{Pb}-\mathrm{Zn}-\mathrm{Cu}$ já constituída. Resta a possibilidade de o hidrotermalismo gerador dessas mineralizações ser cogenético à granitogênese local.

CONCLUSÕES Os eventos mineralizantes que geraram ouro em veios de quartzo localizados na borda norte do Grupo Itajaí (região de Gaspar) e as mineralizações de chumbo, cobre e zinco, localizadas na borda sul (região do Ribeirão da Prata), parecem, conforme sugerido pelos controles estruturais dos depósitos, associados à orogênese que deformou e metamorfisou o Grupo Itajaí e gerou o magmatismo Campo Alegre.

Na fase inicial da deformação houve uma compressão de SE para NW que reativou falhas do embasamento e nucleou um sistema transcorrente (transpressional) sobre as rochas da 
cobertura sedimentar do Itajaí. Nesta fase inicial teriam sido gerados os veios de quartzo do embasamento (Schramm e Subida) com teores elevados de $\mathrm{Au}$, teores baixos de $\mathrm{Ag}$ e sem Bi. Ao final dessa deformação, após, também, o final do magmatismo Campo Alegre, o relaxamento dos esforços teria gerado um sistema transtensional durante o qual foi possível a formação dos veios de quartzo encaixados pelos sedimentos do Grupo Itajaí. Embora numerosos (44 foram descobertos), neles há baixos teores de $\mathrm{Au}$, teores elevados de $\mathrm{Bi}$, e a $\mathrm{Ag}$ é praticamente inexistente, o que os toma de menor interesse econômico.

$\mathrm{Na}$ borda sul, o início das deformações que geraram os veios auríferos do embasamento ao norte de Gaspar, parecem ter en- contrado um corpo mineralizado já formado, ainda não deformado, no Ribeirão da Prata. A compressão de SE para NW reativou a zona de falha (transcorrente?) do Perimbó conferindolhe um deslocamento principal reverso, mergulho acima, com uma componente horizontal dextral. O deslocamento reverso seccionou o corpo mineralizado com falhas de baixo ângulo e rejeito direto. Estas falhas segmentaram o contato norte do corpo mineralizado. $\mathrm{O}$ contato sul foi ativado pelo movimento reverso principal, que destruiu as irregularidades outrora existentes. O final da orogênese, na faixa Ribeirão da Prata, fez-se com a intrusão de domos e diques riolíticos que não foram afetados pelos esforços que geraram as deformações mencionadas.

\section{REFERÊNCIAS BIBLIOGRÁFICAS}

APPI C J. 1988. The late Precambrian Itajaí Group. In: GONDWANA SYMR, 7. São Paulo, 1988. Guide Book... São Paulo, IUGS. p. 1-12.

APPI, C. J. 1991. Análise Estratigráfica da Seção Metassedimentar do Grupo Itajai no Estado de Santa Catarina. Rio de Janeiro. 119 p. (Dissertação de Mestrado, UFRJ).

APPI, C.J. \& SOUZA CRUZ, CE. 1990. Estratigrafía de sequiências na Bacia do Itajaí. In: CONOR. BRAS. GEOL., 36. Natal, 1990. Anais... Natal, SBG. v. 1, p. 93-106.

APPI, C.J.; SOUZA CRUZ, C.E.; BARROCAS, S.L.; FREITAS, E.L. 1987. Modelo deposicional dos turbiditos do Proterozóico Superior do Grupo Itajaí - SC. In: SIMP. SISTEMAS DEPOSICIONAIS DO PRÉCAMBRIANO. Ouro Preto, 1987. Anais... Ouro Preto, BSG/MG. boi. 6 , p. 31-46

BASEI, M.A. S. 1985. O cinturão Dom Feliciano em Santa Catarina. São Paulo. 193 p. (Tese de Doutoramento, IG/USP)

BASEI, M.A.S.; KAWASHTTA, K.; SIGA O, Jr. 1987. Idade, características litoestratigráficas e estruturas do Grupo Itajaí, SC. In: SIMP. SUL-BRAS GEOL., 3. Curitiba, 1987. Ato... Curitiba, SBG/PR. v. 1, p. 93-106.

BORBA, C. \& LOPES, O. F. 1983.0 Grupo Brusque e seu embasamento na região de Itapema, SC. In: SIMP. SUL-BRAS. GEOL., 2. Florianópolis, 1985. Anais... Florianópolis, SBG. p. 24-31.

DE FERRAN, A. \& KISHIDA, A. 1974. Geologia da Mina do Ribeirão da Prata, Blumenau, Santa Catarina. Blumenau, Docegeo. 24 p. (Relatório Inédito).

FERRAZ, L.C. 1921. Excursões Científicas no Estado de Santa Catarina. Annaes da Escola de Minas de Ouro Preto, 17:1-36.

KAUL, P.F.T. 1976. Projeto Brusque - Serra do Taboleiro. Porto Alegre, Convênio DNPM/CPRM. 282 p.
KREBS, A.S.J.; CALDASSO, A.L.S.; LOPES, R.C. 1988. Interpretação preliminar da seqüência deposicional da Bacia do Itajaí na área da folha de Botuverá. In: CONG. BRAS. GEOL., 35. Belém, 1988. Anais... Belém, SBG. v. 2, p. 592-605

KREBS, A.SJ.; LOPES, R.C.; CAMOZZATO, E. 1990b Caracterizacão faciológica do Grupo Itajaí na folha Botuverá (SC). In: CONG. BRAS. GEOL., 36. Natal, 1990. Anais... Natal, SBG. v. 1, p. 82-92.

KREBS, A.S J.; SILVA, M.A.; DIAS, A.A.; CAMOZZATO, E.; LOPES, R.C. 1990a. O Grupo Itajaí na folha Botuverá (SC) - Modelo geométrico/ cinemático e relações com o cinturão granulítico e cinturão metavulcanosedimentar Brusque: instalação, preenchimento e inverso da bacia. In: CONG. BRAS. GEOL., 36. Natal, 1990. Anais... v. 6, Natal, SBG. p. 2966-2975.

ROSTIROLLA, S.P. 1991. Tectônica e Sedimentação da Bacia do Itajaí, SC. Ouro Preto. 131 p. (Dissertação de Mestrado, UFOP).

SCHULZ, A, Jr.; ALBUQUERQUE, L.F.F.; RODRIGUES, C.S. 1970. Geologia da Quadrícula de Florianópolis, SC. Porto Alegre, DPNM. 75 p.

SILVA, L.C. 1987. Geologia do pré-cambriano/eo-paleozóico de Santa Catarina. In: SILVA, L. C.; BORTOLUZZI, C. A. eds. Texto Explicativo para o Mapa Geológico do Estado de Santa Catarina, E: 1/500.000. Santa Catarina, DNPM/CPRM. p. 12-90.
MANUSCRITO A731

Recebido em 11 de junho de 1992 Revisão do autor em 6 de agosto de 1992 Revisão aceita em 14 de agosto de 1992 